Trabajos de Geología, Universidad de Oviedo, 34 : 97-123 (2014)

\title{
Cambios ambientales por los temporales de invierno de 2014 en la costa asturiana (NO de España)
}

\author{
Germán Flor, Germán Flor-Blanco y Carmen Flores-Soriano \\ Departamento de Geología, Universidad de Oviedo, Cl Jesús Arias de Velasco s/n, 33005 Oviedo, España. \\ Grupo de investigación GeoQUO (Geomorfología y Cuaternario, Universidad de Oviedo). \\ (e-mail: gflor@geol.uniovi.es, gfb@geol.uniovi.es, c.flores.soriano@gmail.com)
}

\begin{abstract}
Resumen: Los temporales extraordinarios de febrero y marzo de 2014 provocaron erosiones intensas en las playas y retrocesos de frentes dunares en toda la costa cantábrica y Galicia, incluidos algunos tramos estuarinos externos, así como numerosos destrozos en obras civiles (diques, caminos, sendas, aparcamientos, áreas recreativas, escaleras en playas, mobiliario urbano, etc.). Se detallan algunas playas asturianas y áreas externas estuarinas que experimentaron los procesos más desastrosos, de acuerdo con diferentes modelos de respuestas, donde los frentes dunares retrocedieron irreversiblemente y algunas playas se equilibrarán en el medio plazo. Esta ocasión única permite modelizar la gran variedad de rellenos sedimentarios en playas y el comportamiento de los campos dunares asociados, que se completará en un futuro estableciendo las pautas evolutivas.
\end{abstract}

Palabras clave: playas, dunas, temporal extremo, erosión, retroceso, Asturias

Abstract: The extraordinary wave storms produced in February and March 2014 caused severe beach erosion and dune front retreat in the Cantabrian and Galician coasts, including some outer estuarine areas, as well as many damages in infrastructures (jetties, roads, footpaths, car parks, recreational areas, stairs on the beach, urban furniture, etc.). Some Asturian beaches and outer estuarine areas that experienced the most coastal damages are studied in detail, according to different response models, taking into account those dunar fronts that were irreversibly retreated, and some beaches will reach their short-term equilibrium state. This unique opportunity allows modeling the variety of sedimentary infills of beaches and associated aeolian dune fields which it will be completed in the future by establishing the evolutionary patterns.

Keywords: beaches, aeolian dunes, storm surge, erosion, retreat, Asturias

Es ampliamente aceptado el hecho de que los cambios morfológicos en el ámbito costero son el resultado de procesos e interacciones complejas que actúan a escalas espaciales y temporales relativamente amplias. Habría que añadir el papel antrópico cuyos efectos se dejan sentir, generalmente, de manera local, pero intensa y rápidamente, aumentando su impacto con el tiempo (Augustinus, 2003).
Las playas en general y las cantábricas en particular están mayoritariamente expuestas a oleajes de gran energía lo cual provoca que se erosionen rápidamente y reconstruyan sedimentariamente, aunque de una manera más lenta, como respuesta a la incidencia y paso de frentes de tormenta (Dail et al., 2000; Hill et al., 2004). Incluso pueden alcanzar pautas casi cíclicas de cambio en plazos cortos, variables desde 
unos días a varias semanas (Nordstrom, 1980). No obstante, algunas playas asturianas gozan de mayor protección, generalmente abrigadas a los oleajes del NO, como las situadas al E del cabo de Peńas (Flor, 1978), o que se encajan en promontorios muy salientes con fuertes desniveles acantilados y en desembocaduras fluviales cuyo relleno no enrasa con el perfil litoral.

Se han referido cambios cíclicos de playa: tormentas de olas, seguidas de etapas de calma, como apuntara Nordstrom (1980) o estacionales: invierno y verano (Davis y Fox, 1972), encontrando una relación estrecha entre los cambios morfo-sedimentarios y la variabilidad del nivel energético de los oleajes incidentes, generalmente a partir del parámetro de la altura de ola. Las playas ajustan su morfología y distribución sedimentaria de equilibrio a las variaciones de los oleajes, mareas y otros tipos de influencias (Short, 1999) en lo que constituye el ciclo estacional; se establece así el concepto de perfil de equilibrio asimilable a la distribución geomorfológica de mayor estabilidad o más completa como resultado de oleajes de calma prolongados. Los modelos propuestos se basan en las condiciones del clima de oleaje y la adaptación subsecuente de la playa (Bruun, 1954; Wright et al., 1985; Birkemeier, 1985; Dean, 1991); otros se articulan en torno a la respuesta directa con ocasión de tormentas de fuerte energía, tanto individuales como de manera agrupada (Lee et al., 1998), así como el de Yates et al., (2009a) que desarrollan un modelo de cambio costero en el que incluyen los tamaños finos y medios para climas de oleaje moderados y clamas prolongadas, respectivamente. No obstante, procesos muy energéticos sobre playas no implican necesariamente una erosión, lo mismo que los de poca energía no se suceden con una acreción (Sénéchal et al., 2009). En el caso de algunas playas apoyadas (Masselink y Pattiaratchi, 2001), las variaciones estacionales se deberían a los cambios en dirección de la deriva litoral (direcciones reversible u opuestas).

Se simplifica el proceso de tormentas en playas a través de la erosión de la playa emergida, que se resuelve en una superficie o perfil aplanado, y el transporte del volumen sedimentario hacia la zona submareal, en muchos casos como una o varias barras arenosas sumergidas (Harper, 1980; Roberts et al., 2013), que experimentarán diversos procesos hidrodinámi- cos en función del rango mareal y del clima de oleaje (Wijnberg y Kroon, 2002).

Tormentas excepcionalmente intensas ocurridas en los últimos años han espoleado el interés para estudiar la frecuencia, el impacto y el papel de tormentas (Ciavola et al., 2011) de un modo particular en la costa oriental de USA, donde se extienden islas-barrera (Anthony, 2013), así como en el SE asiático (ANDROID, 2013), pero últimamente también en playas encajadas (Loureiro et al., 2014). El temporal de finales de diciembre de 2008 en las costas de Cataluña, sirvió de justificación para aplicar un sistema de predicción morfodinámica (Sánchez-Arcilla et al., 2012), como herramienta de alarma temprana y de gestión costera. Existen también algunas aproximaciones a la predicción de situaciones de tormenta y sus efectos en la costa gaditana (Rangel-Buitrago y Anfuso, 2013).

Los estudios para conocer los cambios costeros a escalas de tiempo anual y de algunos lustros son sin duda más relevantes desde la perspectiva social, vinculando las interacciones humanas y el ambiente dinámico costero (Ruggiero et al., 2005).

Los temporales del invierno de 2104, con sucesos extremos a primeros de los meses de febrero y marzo, afectaron a las costas de Galicia y del Cantábrico, materializándose principalmente en procesos de erosión sobre los ambientes morfo-sedimentarios. Estos eventos extraordinarios en Asturias, la comunidad autónoma y municipios costeros más afectados por los temporales, provocaron, solamente en el primero de febrero, daños de unos 12,11 millones de euros, mientras que los bienes de titularidad estatal en Galicia, Principado de Asturias, Cantabria y País Vasco ascienden a 150 millones de euros y los particulares a 52,05 millones de euros (http://www.magrama.gob.es/es/prensa/noticias/ miguel-arias-ca $\%$ B1 ete- $\%$ E2\% 80\%9Cdesde-el-inicio-de-los-temporales-en-la-cornisa-cant $\% \mathrm{C} 3 \% \mathrm{~A} 1$ brica-y-galicia-el-gobierno-trabajo-en-la-identificaci\%C3\%B3n-y-valoraci\%C3\%B3n/tcm7-316377-16).

Representa una oportunidad única para conocer los cambios habidos y establecer las pautas de cambio de gran amplitud temporal y espacial (Haxel y Holman, 2004), entre los que habría que referenciar los ciclos de la NAO (referidos en el área meridional de la Península Ibérica) donde se establecen intervalos 
a lo largo de 40 años con una periodicidad de 3 a 7 ańos (Rodríguez Ramírez et al., 2000). Benavente et al. (2014) encuentran una dependencia entre los valores negativos en invierno y el número, duración e intensidad de los temporales en esa estación.

En zona de huracanes, las playas responden con una erosión intensa seguida de una recuperación lenta (Morton et al., 1994), pero cada playa lo hace de diferentes maneras en función de su relleno sedimentario (volumen del prisma y granulometría), orientación, amplitud de las bermas, etc. Se han detallado procesos en playas de la costa atlántica de Nueva Escocia (Canadá), donde se han monitorizado los efectos de grandes temporales en la estabilidad de la costa (Taylor et al., 2008), alguno de cuyos efectos también se han detectado en Asturias.

A lo largo del perfil litoral expuesto directamente a los oleajes, la variedad de ambientes costeros ha experimentado algunas incidencias sumamente contrastadas, de manera más acusada sobre las playas, que son las más ampliamente representadas, y más aún sobre las dunas asociadas. Han pasado por el episodio de mayor erosión posible, desmantelándose principalmente el sedimento de las zonas supra e intermareal superior y franja dunar limitante para trasladarlo a la playa sumergida.

En este trabajo, se describen las 65 playas y sistemas dunares más afectados, de mayor uso estival, modelizando las respuestas principales sobre estos últimos conjuntos morfo-sedimentarios, perfectamente extrapolable al resto del Cantábrico. La particularidad de algunos segmentos de esta costa se caracteriza en la existencia de numerosas playas de gravas, adonde no han llegado las fracciones arenosas que se transportan por deriva litoral desde los estuarios mayores vinculados a sistemas fluviales de gran entidad. Éstas son escasamente utilizadas por el gran público, lo que motiva un gran desinterés si se compara con las anteriores.

\section{Metodología}

Se han llevado a cabo diferentes campañas de campo en varias etapas después del primer evento de febrero y el último de marzo, que se ha continuado hasta entrada la primavera y parte del verano, con la toma de documentación fotográfica y medidas in situ del retroceso del límite playa/dunas. Se han consultado ortofotografías (PNOA) a escala 1:5.000 de los años 2009 y 2011, cedidas por el Servicio de Cartografía del Principado de Asturias, de Google Earth desde 2001 a 2013 y de la herramienta Bing Maps 3D de 2013. Se ha rastreado la exhaustiva información gráfica y escrita, recogida por la prensa regional y la aportada por el Principado de Asturias (Consejería de Fomento y Vivienda). También los documentos de los Ministerios de Fomento y Agricultura, Alimentación y Medio Ambiente, algunos contenidos en el BOE (no 46 de 22.2.2014) o el BOPA para reposición de obras civiles, numerosos vídeos de la TPA (televisión autonómica), particulares en internet, etc.

Se maneja un archivo fotográfico amplio de la costa asturiana, alguna de cuyas instantáneas se han ofrecido por la prensa regional digital (La Nueva España y El Comercio) y vídeos de YouTube, accesibles desde internet, incluyendo el archivo histórico de los autores y las tomadas directamente con ocasión de estos temporales, que permiten cotejar los estados previos, posteriores y la evolución subsiguiente.

Por último, se ha procedido a medir el retroceso dunar acaecido en el invierno de 2014, mediante un distanciómetro láser Leica (D5) y el posicionamiento de los frentes dunares a partir de un GPS modelo Garmin.

\section{La costa asturiana}

Se extiende entre las costas de Lugo y Cantabria (NO de España), con una alineación general O-E, pero con numerosos tramos cambiantes a $\mathrm{NO}$ y NE entre los que destaca la proyección más septentrional del cabo de Peñas o el escalón de Lastres (Fig. 1). La adaptación del perfil litoral a la competencia diferencial de las rocas aflorantes y su distribución estructural, así como la existencia de grandes fracturas determinan esta particularidad. La gran irregularidad de esta costa hace que tenga una gran longitud en su costa expuesta, en torno a 391,85 km, sin contabilizar los márgenes afectados por las pleamares vivas hasta su disipación aguas arriba de los estuarios mayores y menores, todos con magnitudes muy contrastadas. 
Es una costa rocosa acantilada culminada por alguna superficie plana de erosión (rasa), las mayores de origen continental (Flor y Flor-Blanco, 2014a). Los desniveles alcanzan cifras métricas en el occidente, incrementándose hasta máximos de 90-130 m en el entorno de la desembocadura del Nalón, que se continúa irregularmente hacia Cantabria y País Vasco, ambas comunidades con esta misma característica.

La configuración de la línea de costa en Asturias se manifiesta, además de la abrasión diferencial mencionada, con predominio del perfil rocoso acantilado, $y$ se completa con los rellenos sedimentarios para conformar estuarios, playas de gravas, mixtas y arenosas apoyadas en promontorios que, en algunos casos, han desarrollado sistemas dunares asociados. Algunas playas se han dispuesto sobre desembocaduras de arroyos costeros, adquiriendo la típica morfología triangular en planta, y otras forman parte de las barreras confinantes de estuarios de mayor magnitud en cuyo caso son extensas y contienen amplios y complejos campos dunares. Otras reciben algún arroyo o regato costero el cual ha construido frente a la desembocadura un prisma de sedimentos más groseros (gravillas, gravas e, incluso, cantos), eventualmente recubiertos por las arenas en sus etapas de equilibrio.

La propia singularidad de esta costa acantilada de Asturias ha propiciado las aportaciones de fracciones groseras (cantos, gravas y gravillas) a las playas, pero también algunos ríos, como el Sella (estuario y playa de Santa Marina) y arroyos costeros de mayor competencia energética han contribuido a un incremento sedimentario adicional. Son los casos de Porcía: estuario y playa de Porcía, Esva: playas de Cueva a Ballota (Fig. 1), Esqueiro: playa de San Pedro de Luiña y Uncín: playas de la Concha de Artedo, Aguilar y Las Llanas, Acebo: playa de Vega y Bedón: playa de San Antolín de Bedón.

La disposición de las playas arenosas asturianas, separadas entre sí mediando numerosos segmentos rocosos, se generaron a partir de las aportaciones masivas de arenas siliciclásticas por sistemas fluviales y, localmente, por la incorporación de bioclastos calcáreos costeros, aportados principalmente desde los acan-

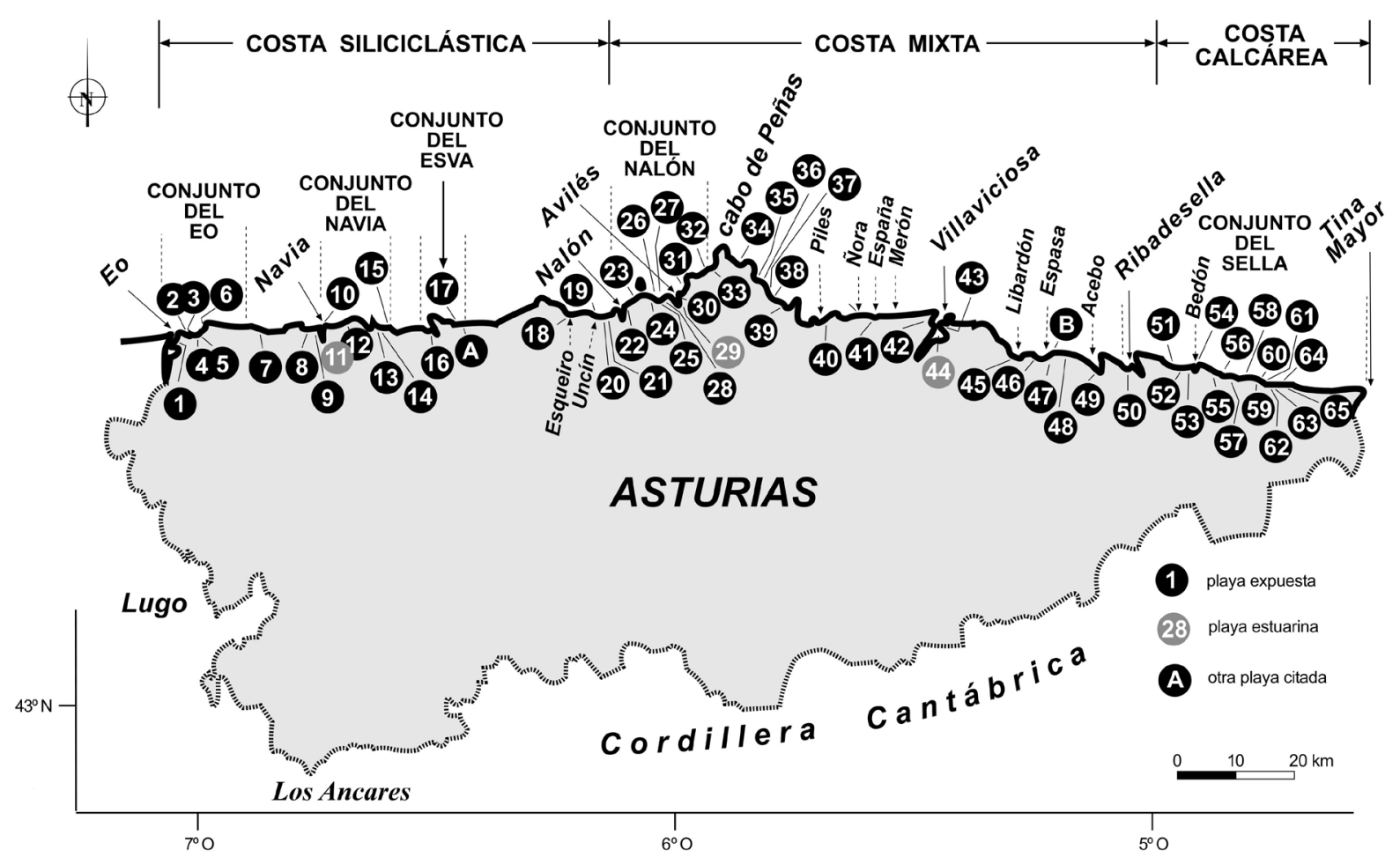

Figura 1. La costa de Asturias se sectoriza según el sustrato rocoso dominante, donde se desarrollan estuarios principales y secundarios (tamaños de letra cursiva mayor y menor, respectivamente). Se detallan las playas afectadas por los temporales de invierno de 2014 (números citados en el texto). Otras playas citadas: A (Ballota) y B (El Viso). 
tilados, más importantes en áreas de afloramientos oceanográficos (Flor et al., 1982). Los cambios del nivel del mar, especialmente el último ciclo eustático, removilizaron grandes volúmenes sedimentarios de modo que, desde el último evento transgresivo Flandriense, se configuró la distribución de la mayor parte de los conjuntos sedimentarios costeros.

Los conjuntos de sistemas de playas y dunas se distribuyen de acuerdo con los ríos de mayor magnitud (Fig. 1), con un gran desarrollo desde la desembocadura hacia el E, debido a la deriva litoral, destacando los del Eo, Navia y Nalón. Los del Esva y Sella apenas suministraron volúmenes arenosos suficientes como para generar excesos arenosos susceptibles de generar campos dunares. En el tramo costero comprendido entre los estuarios de Villaviciosa y Ribadesella, se construyeron los estuarios de Esqueiro, Nora y España, Libardón y Espasa y el muy reducido del Acebo, que se colmataron durante la trasgresión Flandriense, pero han permitido la construcción de campos dunares menores.

Los ríos que mayores volúmenes arenosos han aportado son los del Navia y Nalón (y su gran afluente, el Narcea) que han servido para la formación de extensas playas y campos dunares asociados. El Sella, casi en exclusiva, ha sido responsable de la formación de las playas del oriente asturiano sobre rocas calcáreas, junto con la cuenca menor del Bedón, y el Cares-Deva (estuario de Tina Mayor), que afectó a la vecina costa de Cantabria.

Todo apunta a que, actualmente, funcionan como células morfodinámicas y sedimentarias relativamente independientes. Mucho más evidente se manifiesta en las constituidas por gravas y gravillas que ocupan volúmenes menores, éstas desarrolladas gracias al funcionamiento de los acantilados de la posplaya, como áreas fuente del material sedimentario, y más escasamente de las descargas de algunos ríos costeros.

\section{Agentes dinámicos}

\section{Generalidades}

Los vientos se reparten en un abanico direccional amplio que, en términos promediados anuales (Fig. $2 \mathrm{~A}$ ), son dominantes del tercer cuadrante, aunque intervienen escasamente en el modelado costero debido a la orientación general O-E y a la pertenencia a una costa rocosa abrupta cuyos sistemas morfo-sedimentarios se desarrollan al pie del sistema acantilado. Los del $\mathrm{E}$ y $\mathrm{O}$ les siguen en importancia, estos últimos especialmente intensos (LEAS, 2012), participando activamente en la formación de dunas lingüiformes. Los incluidos dentro del cuarto cuadrante juegan un papel destacado en la formación de campos dunares en general y de cordones en particular, mientras que los del primer cuadrante intervienen preferentemente cuando las playas se orientan en dirección NO-SE.

Los oleajes dominantes son del $\mathrm{NO}$, aunque abarcan un espectro desde el $\mathrm{NO}$ al NE y, con alturas significantes superiores a $1,7 \mathrm{~m}$, pueden considerarse como de olas de temporal. La máxima altura significante, desde los primeros registros en 1998 (boya de cabo de Peñas), es de 12,18 m (Fig. 2B) y la máxima altura de ola alcanzada fue de $23,3 \mathrm{~m}$.

Las mareas son semidiarias y los rangos medios entran dentro de la categoría de mesomareal, con mínimos de 1,0 m y máximos de 4,65 m en Gijón, si bien en régimen extremal llegaría a $4,95 \mathrm{~m}$ y al añadir la marea meteorológica hasta 5,44 m (20 de marzo de 2007), según datos de CONGEO (2013).

El ascenso del nivel del mar en el área oriental del Cantábrico se ha cuantificado en tasas variables desde $1,9 \mathrm{~mm} /$ año (Leorri et al., 2008) a 1,7 $\pm 0,2 \mathrm{~mm} /$ año (García-Artola et al, 2014) a lo largo del siglo XX. Este factor condiciona el retroceso de los campos dunares desde hace varias décadas, como son los casos de las playa de Vega (Flor y Flor-Blanco, 2009) y Mexota, Frexulfe, Barayo y Otur (Flor y Flor-Blanco, 2014b), así como en Bayas y Carniciega (Flor y Flor-Blanco, 2014c).

\section{Vientos y oleajes de tormenta}

Durante el otońo e invierno de 2013-2014, la costa cantábrica fue afectada por vientos de poniente, con rachas que alcanzaron en el Cantábrico occidental hasta $174 \mathrm{~km} / \mathrm{h}$, como parte del paso de sistemas frontales de manera continuada, asociados a borrascas atlánticas que han ocasionado numerosos temporales con 
tres episodios de varios días de duración (Instituto de Hidráulica Ambiental de Cantabria, WebUC: http:// www.ihcantabria.com/es/newss/item/966-investigadores-de-ih-cantabria-interpretan-los-datos-de-la-red-vigia-para-explicar-los-temporales-de-este-invierno).

Desde primeros de 2014, se produjeron perturbaciones reseñables en las corrientes de chorro sobre el Pacífico y, más aún, en el Atlántico N, motivadas por lluvias intensas y persistentes en Indonesia y las regiones tropicales del Pacífico O, así como fríos excepcionales en Canadá y Estados Unidos (Instituto de Hidráulica Ambiental de Cantabria, WebUC). El índice NAO se mantuvo en fase positiva a lo largo de los meses de febrero y marzo (informe mensual climatológico de Aemet, 2014).

Se ha seleccionado el conjunto de datos online meteorológicos y de las mareas del puerto de El Musel de Gijón (Tabla I). Los vientos tienen poca representatividad en la estación al interponerse el cabo de Torres (120 m de altura), justo al $\mathrm{O}$ a unos $700 \mathrm{~m}$ de distancia, mientras que la presión barométrica y la oscilación mareal sirven para conocer mejor las elevaciones del nivel del mar. Estas presiones registradas de 1.017 y 1.005 mbar supondrían una bajada o elevación de 4,5 cm y $11,5 \mathrm{~cm}$, respectivamente, aplicando la corrección barométrica incluida en los Anuarios de Mareas (Mederos Martín, 2009), sobre la oscilación mareal, en que la pleamar se constituye en el parámetro principal, así como la hora de ocurrencia. Los vientos del tercero y cuarto cuadrante incrementarían las alturas mareales.

A partir de los datos obtenidos en las dos boyas de la Red de Vigilancia de Cantabria de la Consejería de Medio Ambiente, Ordenación del Territorio y Urbanismo (http://www.redvigia.es/), el Instituto
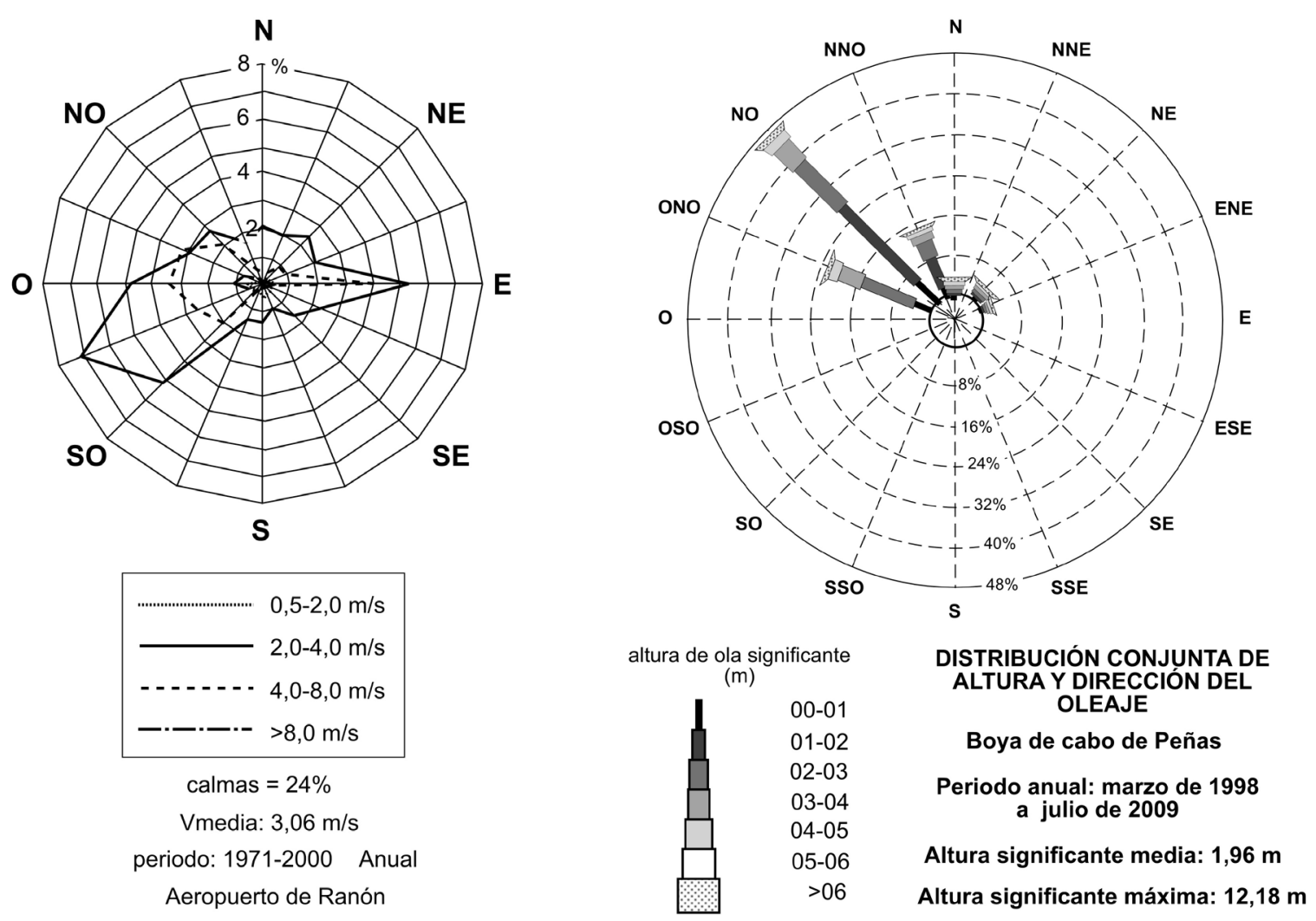

Figura 2. A) Promedios direccionales y de velocidad anuales de vientos en el aeropuerto de Asturias (costa central) con datos de AEMET (Pinazo Ojer, 2010). B) Direcciones y alturas medias anuales de la boya de cabo de Peńas, situada en las coordenadas: 6.17 $\mathrm{O}-43.74^{\circ} \mathrm{N}$ para el periodo 1998-2009 (Puertos del Estado, 2010: http://www.puertos.es/oceanografia_y_meteorologia/redes_de_medida/index.html). 


\begin{tabular}{|c|c|c|c|c|c|c|}
\hline \multicolumn{7}{|c|}{ Día: 02/02/2014 } \\
\hline \multicolumn{2}{|c|}{$\begin{array}{l}\text { TEMPERATURA } \\
\left({ }^{\circ} \mathrm{C}\right)\end{array}$} & \multicolumn{3}{|c|}{$\begin{array}{c}\text { VIENTO } \\
\text { velocidad }(\mathrm{m} / \mathrm{s})\end{array}$} & \multirow{2}{*}{$\begin{array}{c}\text { PRESIÓN } \\
\text { (mBar) } \\
(\mathrm{mBar})\end{array}$} & \multirow{2}{*}{$\begin{array}{c}\text { HUMEDAD } \\
\text { RELATIVA } \\
\%\end{array}$} \\
\hline máxima & mínima & media & ráfaga & dirección & & \\
\hline 9,60 & 6,20 & 9,99 & 20,06 & $324^{\circ}$ & 1.017 & 83 \\
\hline \multicolumn{7}{|c|}{ Día: 03/03/2014 } \\
\hline \multicolumn{2}{|c|}{$\begin{array}{l}\text { TEMPERATURA } \\
\left({ }^{\circ} \mathrm{C}\right)\end{array}$} & \multicolumn{3}{|c|}{$\begin{array}{c}\text { VIENTO } \\
\text { velocidad }(\mathrm{m} / \mathrm{s})\end{array}$} & $\begin{array}{l}\text { PRESIÓN } \\
\text { (mBar) }\end{array}$ & $\begin{array}{l}\text { HUMEDAD } \\
\text { RELATIVA }\end{array}$ \\
\hline máxima & mínima & media & ráfaga & dirección & (mBar) & $\%$ \\
\hline 13,50 & 7,00 & 13,00 & 34,50 & $345^{\circ}$ & 1.005 & 92 \\
\hline
\end{tabular}

\begin{tabular}{|c|c|c|c|}
\hline \multicolumn{2}{|c|}{ PLEAMARES } & \multicolumn{2}{|c|}{ BAJAMARES } \\
\hline mańana & tarde & mańana & tarde \\
\hline horalmetros & horalmetros & horalmetros & horalmetros \\
\hline 04:58/4,79 & $17: 22 / 4,40$ & $11: 07 / 0,18$ & $23,34 / 0,33$ \\
\hline \multicolumn{2}{|c|}{ RANGO: $4,61 \mathrm{~m}$} & \multicolumn{2}{|c|}{ RANGO: $4,07 \mathrm{~m}$} \\
\hline \multicolumn{4}{|c|}{ Día03/03/2014 } \\
\hline \multicolumn{2}{|c|}{ PLEAMARES } & \multicolumn{2}{|c|}{ BAJAMARES } \\
\hline mañana & tarde & mañana & tarde \\
\hline horalmetros & horalmetros & horalmetros & horalmetros \\
\hline $04: 38 / 4,70$ & $16: 58 / 4,40$ & $10: 44 / 0,15$ & $23,02 / 0,24$ \\
\hline \multicolumn{2}{|c|}{ RANGO: $4,55 \mathrm{~m}$} & \multicolumn{2}{|c|}{ RANGO: $4,16 \mathrm{~m}$} \\
\hline
\end{tabular}

Tabla 1. Registros meteorológicos y de mareas del puerto de El Musel (Autoridad Portuaria) los días 2 de febrero y 3 de marzo de 2014 (Servicios Online. Puertos del Estado. Ministerio de Fomento).

de Hidráulica Ambiental "IH Cantabria” (WebUC: http://www.ihcantabria.com/es/) hace referencia a lo inusual de este comportamiento con temporales más largos (hasta 7 días más) según una secuencia encadenada con ocurrencia muy corta entre ellos, niveles de la energía altos y la tendencia a incrementar la energía de los oleajes en los últimos años con la excepcionalidad de este invierno.

La situación meteorológica se caracterizó por la llegada de una sucesión de borrascas profundas procedentes de Terranova e Islandia y al $\mathrm{N}$ de las Islas Británicas, alimentadas por aire frío, que se centraron en las Islas Británicas en cuanto a la aparición de inundaciones intensas e históricas, NO y N España, así como en la costa atlántica de Francia. Coincidieron con el desplazamiento del anticiclón al $\mathrm{S}$ de las Azores y la circulación zonal de la corriente en chorro de vientos en altura con rachas que superaron los umbrales en numerosos días de los meses de enero a marzo (Tabla I), algunos de los que precedieron a los mayores temporales con cifras superiores a los 70 $\mathrm{km} / \mathrm{h}$ (30 de enero) y $80 \mathrm{~km} / \mathrm{h}$ ( 2 de marzo), si bien varios días previos se caracterizaron por esta característica de agitación extrema.

Simplificadamente, el mar de fondo generado por borrascas atlánticas, unido al mar de viento debido a un frente pequeño, el ciclo lunar y la pleamar viva, explican los destrozos del invierno sufridos en todo el litoral cantábrico. Este evento catastrófico ha afectado a las costas de Galicia y todo el Cantábrico, especialmente los días 1 y 2 de febrero (tormenta Nadja o temporal Hércules), un mes en que han ocurrido veinticinco temporales de viento, lluvias y oleaje en la costa $\mathrm{N}$ de España (BOE, n 46, de 22 de febrero de 2014), y 3 de marzo (tormenta Christine). Se formaron vientos intensos con rachas fuertes (Tabla II) y grandes olas en la costa, que actuaron con mayor incidencia sobre el borde costero en cuanto a una sobreelevación de agua durante una pleamar viva. Las rachas máximas de viento $(\mathrm{km} / \mathrm{h})$ que superaron los umbrales (Tabla II) se refieren 


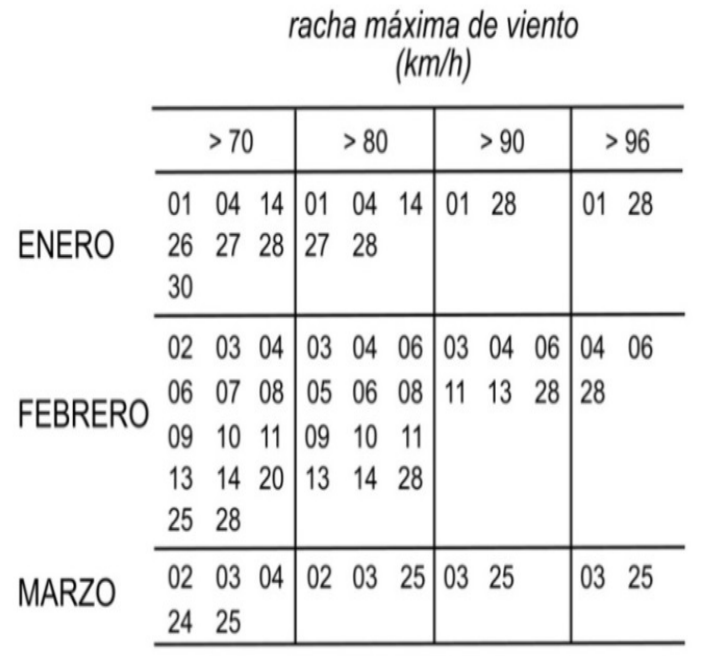

(dias del mes de 2014 en que se superaron los umbrales) AEMET: $h$ ttp://www.aemet.es/es/serviciosclimaticos/datosclimatologicos/superacion_umbrales?p $=33 \& w=0$
Tabla II. Rachas máximas de viento $(\mathrm{km} / \mathrm{h})$, registradas en el aeropuerto de Asturias en los días de los meses de enero, febrero y marzo de 2014 en que se superaron los umbrales. a partir de velocidades superiores a $120 \mathrm{~km} / \mathrm{h} \mathrm{du}$ rante un intervalo de 3 segundos. Están estrechamente relacionadas con la cobertura aseguradora de riesgos meteorológicos (http://atsistemas.com/ expresat/2013/04/sobre-los-riesgos-de-las-rachasmaximas-de-viento/).

El agua de mar invadió paseos, calles, diques, muros y paseos marítimos de numerosas ciudades y villas costeras, que ocasionaron grandes destrozos en la franja del dominio público marítimo-terrestre, playas y puertos principalmente, y sobre infraestructuras municipales, carreteras, vías urbanas, paseos marítimos, embarcaciones, diques, comercios, viviendas y garajes. Fueron importantes las inundaciones en los estuarios de Navia, Ribadesella y Villaviciosa con mayor incidencia en las superficies urbanizadas. De manera lateral, un gran número de aves de mar abierto, como son el alca (Alca torda), el arao común (Uria aalgae) y el frailecillo atlántico (Fratercula arctica), así como algunos cormoranes (Phalacrocorax aristotelis) y gaviota patiamarilla (Larus michahellis), han muerto siendo arrastradas hasta el litoral cantábrico.

Los avances meteorológicos de los meses de febrero y marzo en Asturias (Aemet) revelan que, en la madrugada del día 2 de febrero, se registraron olas de $11,25 \mathrm{~m}$ de altura en alta mar, que coincidió con una pleamar de coeficiente mayor de 100 . Se acompañó por vientos persistentes del SO, finalizando con otro episodio de lluvias intensas y viento fuerte, que superó los $80 \mathrm{~km} / \mathrm{h}$. En la boya de la Universidad de Oviedo, situada a unos $4 \mathrm{~km}$ al NE de Cudillero, el 1 de febrero se registró una ola de $20,87 \mathrm{~m}$ de altura y la significante fue de $10,54 \mathrm{~m}$.

Durante los primeros días de marzo, ocurrió un nuevo temporal de oleaje extraordinario, acompañado de fuertes vientos, de modo que hasta el día 5 dominó la circulación intensa de componente $\mathrm{O}$ y hubo precipitaciones abundantes. La altura significante de ola fue de 11,60 m en la boya del Cabo de Peñas, que superó el máximo histórico mensual. Durante los últimos diez días del mes, se sucedieron diferentes depresiones con precipitaciones que fueron más abundantes entre los días 20 y 26.

Conde Criado (2014) recopiló los datos de las alturas de ola significantes, procedentes del catálogo del Centro Europeo de Predicción a Plazo Medio (ECMWF); utilizó en este caso la estación POS05, situada al NNO de cabo de Peñas (45.00N-006.00O), para el periodo 1 de octubre de 2013 a 10 de marzo de 2014 (Fig. 3A y B). Se sucedieron oleajes intensos no excepcionales con alturas similares al periodo otoño-invierno de 2013 y 2014, repartidos en episodios aislados, pero caracterizados por una recurrencia en que el promedio de alturas de ola significativas ha sido muy elevado. 


\section{Catálogo de playas afectadas}

Los numerosos entornos de playas y campos dunares se asocian, fundamentalmente, al tipo de sustrato rocoso dentro de la cadena varisca del NO de la península Ibérica (Lotze, 1945): costa siliciclástica sobre la Zona Asturoccidental-leonesa (alternancias de cuarcitas y limolitas paleozoicas), y costa mixta: Zona Cantábrica con calizas areniscas, cuarcitas y limolitas paleozoicas y mesozoicas y calcárea con alguna intercalación cuarcítica del Paleozoico. Se agruparon en relación con las aportaciones arenosas de ríos principales, los occidentales enraizados en los Ancares lucenses y leoneses (Eo y Navia) y en la cordillera Cantábrica (Nalón, Sella y Cares-Deva), pero pueden depender de los numerosos ríos y arroyos intermedios y costeros, particularmente notorios al $\mathrm{E}$ del cabo de Peñas (Fig. 3).
Las playas expuestas arenosas, de gravas y mixtas, algunas estuarinas y campos dunares asociados, experimentaron los mayores cambios ambientales negativos, bien sea migrando los depósitos hacia tierra o provocando frentes erosivos, que, desde la perspectiva de su estabilidad morfo-sedimentaria, se detallan seguidamente (Fig. 2) de O a E. En algunos estuarios, como Eo, Navia y Villaviciosa, mantos arenosos de espesor centimétrico a decimétrico migraron hacia el interior sobre las llanuras arenosas y los canales principales, recubriendo algunas dunas estuarinas.

Se incluyen referencias a algunos destrozos de elementos constructivos o de servicios de manera muy sucinta. En este caso, las incidencias del oleaje y las respuestas se han debido a causas totalmente naturales, si bien algunas playas en retroceso por causas antrópicas indirectas, han sufrido un proceso magnificado.
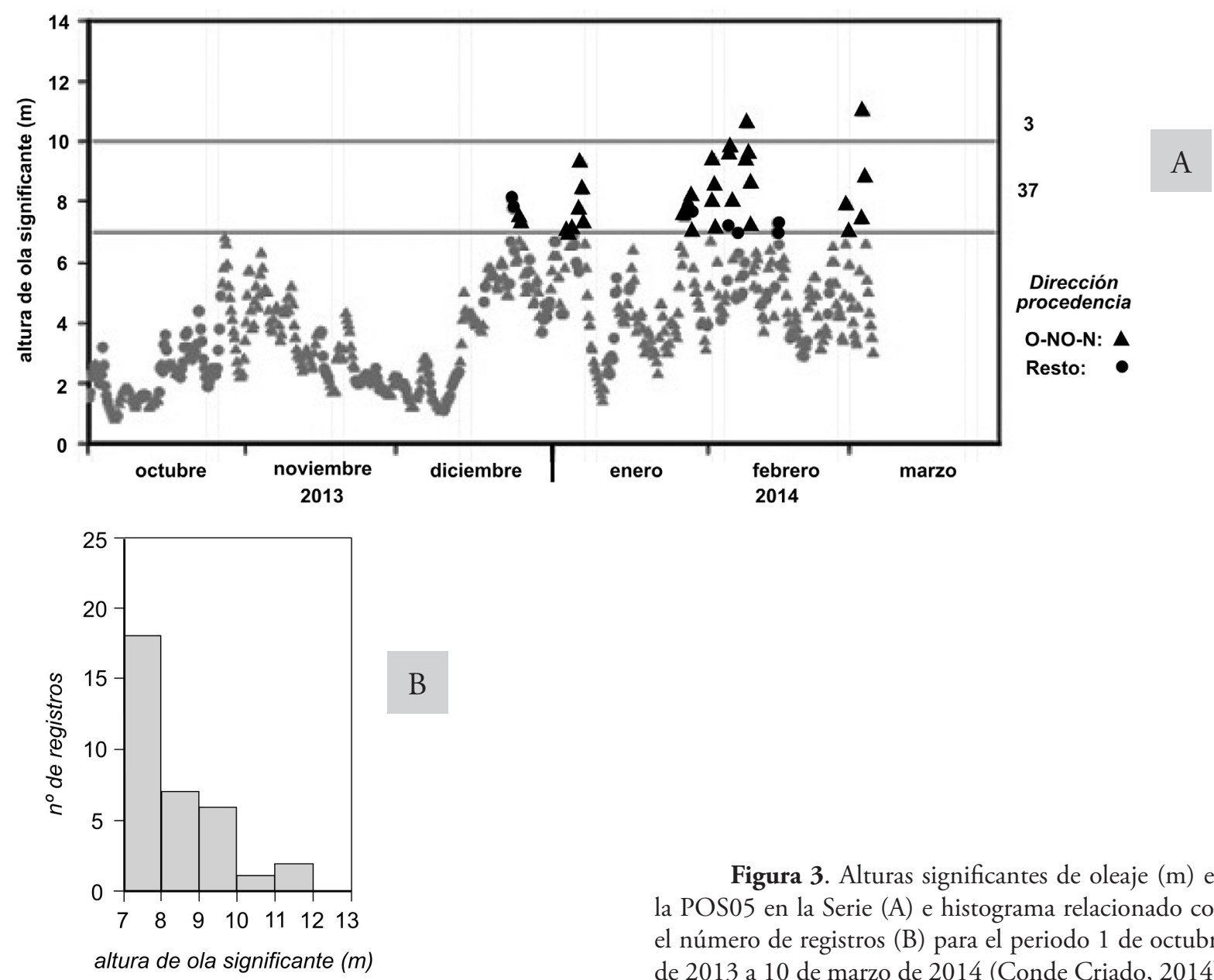

Figura 3. Alturas significantes de oleaje $(\mathrm{m})$ en la POS05 en la Serie (A) e histograma relacionado con el número de registros (B) para el periodo 1 de octubre de 2013 a 10 de marzo de 2014 (Conde Criado, 2014). 
1. Arnao (Castropol). Pérdida de arena con incremento de la proporción de gravas, produciéndose el afloramiento de la plataforma rocosa. Se ha generado un argayo en el costado $S$ de la playa, que ha descalzado la carretera.

2. Penarronda. En el frente dunar, se desarrolló un escarpe erosivo, cuyo desnivel medio suele ser decimétrico, y un retroceso horizontal de algún metro en la mitad occidental. En la mitad oriental, se generó un abanico de tormenta amplio, que se adentró hasta $75 \mathrm{~m}$. Hubo pérdida de mobiliario urbano (parte de las pasarelas de madera) en una longitud de 100 $\mathrm{m}$. Se consolidó el incremento de la superficie supramareal y el retroceso del campo dunar inactivo.

3. Mexota. La duna remontante fue erosionada, principalmente en el costado oriental (media de 5,0 $\mathrm{m}$ de desnivel), quedando ahora una amplia superficie dunar de mayor pendiente desprovista de vegetación (Fig. 4A). Se detectó un retroceso de las dunas, incrementado en este evento extraordinario.

4. Sarello (Serantes). Incremento sustancial de la playa supramareal por erosión del cordón dunar, del que solamente ha quedado un retazo en el extremo occidental en lo que constituía la barrera confinante del estuario del río Tol. Tuvo lugar la intrusión de un abanico de tormenta en el estuario (Fig. 4B). Se ha estimado una pérdida de arena de unos 2,0 $\mathrm{m}$ de potencia en la playa. Algo de erosión de mobiliario y eliminación de un lavapiés.

5. Anguileiro (Tapia de Casariego). Han desaparecido totalmente las escasas dunas residuales del costado occidental de la playa superior. La intrusión de un extenso y delgado manto de arenas, como un abanico de tormentas, avanzó sobre el estuario del río Anguileiro, donde se ubica el campo de futbol de A Xungueira (Fig. 4C), sobre cuyo césped se produjo una sedimentación laminar. En el borde oriental, la denominada como playa del Murallón de Tapia, también ha perdido abundante arena. Rotura de los muros y la plataforma de acceso a la playa.

6. Porcía. Pérdida de arena con mayor concentración de gravas y gravillas que rellenaron parcialmente el área recreativa al desbordar la berma, en lo que representa una migración generalizada del sistema hacia tierra.
7. Pormenande (La Caridad). Rebase de gravas hacia tierra en la esquina oriental y daños en el área recreativa donde desemboca el arroyo del mismo nombre.

8. Ortiguera. Dentro de este estuario muy incipiente, los escasos depósitos de playa, también de gravas, que se repartían en varios segmentos, así como los depósitos de gravas y gravillas aportados por el arroyo Fundión, desaparecieron en su totalidad para alojarse en los fondos más profundos, permanentemente sumergidos a lo largo de todo el muelle exterior.

9. Foxos. También perdió gran cantidad de arena y fue totalmente destrozado el mobiliario de la propia playa y del área recreativa anexa.

10. Navia o Vega de Arenas. Sistema de playa/ dunas que forma parte de la barrera confinante del estuario. La totalidad de las áreas oriental y buena parte de las zonas central y occidental han quedado sometidas a la intrusión de un abanico arenoso de tormenta de espesor centimétrico a decimétrico (Fig. 4D), aunque con recesiones no tan acusadas (variables entre 1,7 y 4,7 m). Además, en un episodio terminal del temporal, el tercio occidental ha retrocedido ligeramente formando un escarpe con desnivel decimétrico. La barrera avanzó inexorablemente tierra adentro, como se ha comprobado en observaciones en la última década.

11. La Poza. En este entorno de la bahía arenosa del estuario de Navia, generado artificialmente en el siglo pasado por la escollerización del canal principal, el intercambio mareal está muy disminuido desde la construcción del paseo marítimo. No obstante, ha permitido la intrusión de arenas desde el canal, más aún con ocasión de estos temporales. Se está traduciendo también en la decantación de limos y arcillas y materia orgánica en la mitad oriental que dificultan el uso playero. La playa estuarina meridional, que formaba parte de la barrera confinante antigua, debido a vientos del NO sobre la ensenada con formación de oleaje interno en estos días de temporal, coincidiendo con pleamares vivas, ha retrocedido algunos decímetros en determinados sectores, sumándose al retroceso general que se manifiesta desde hace 20 años. 
A
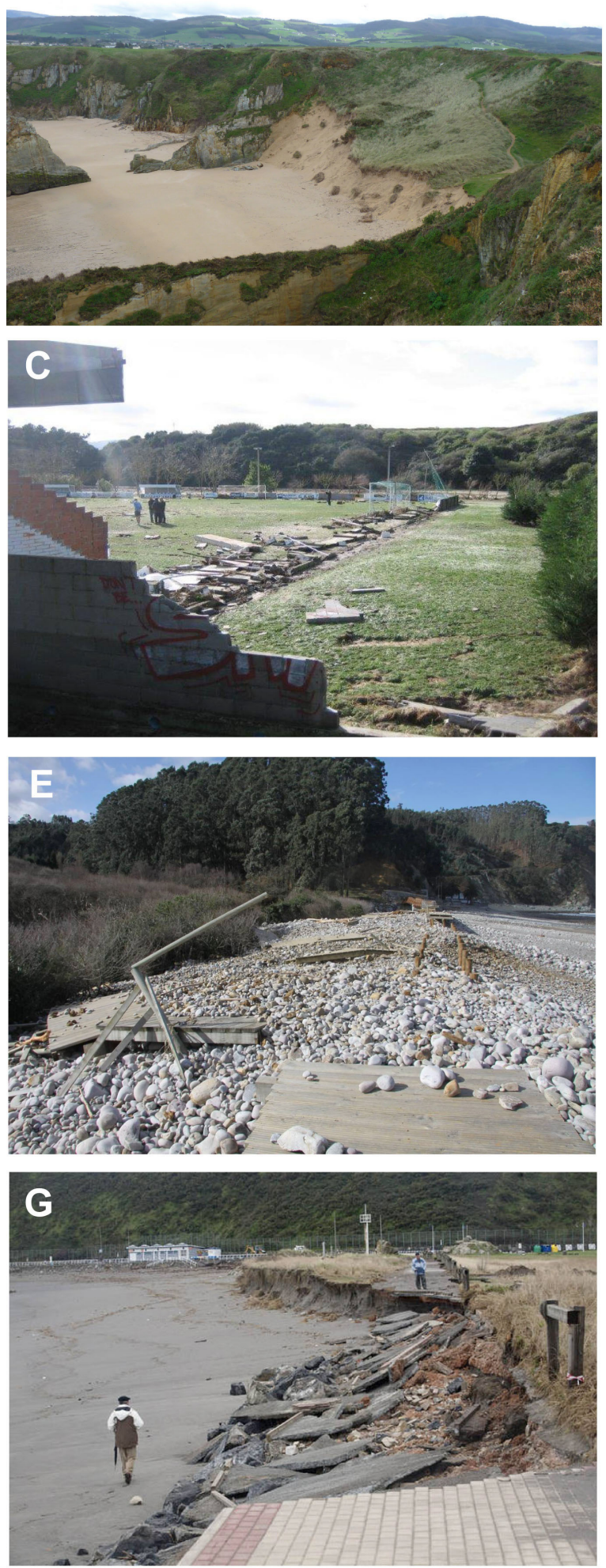

B
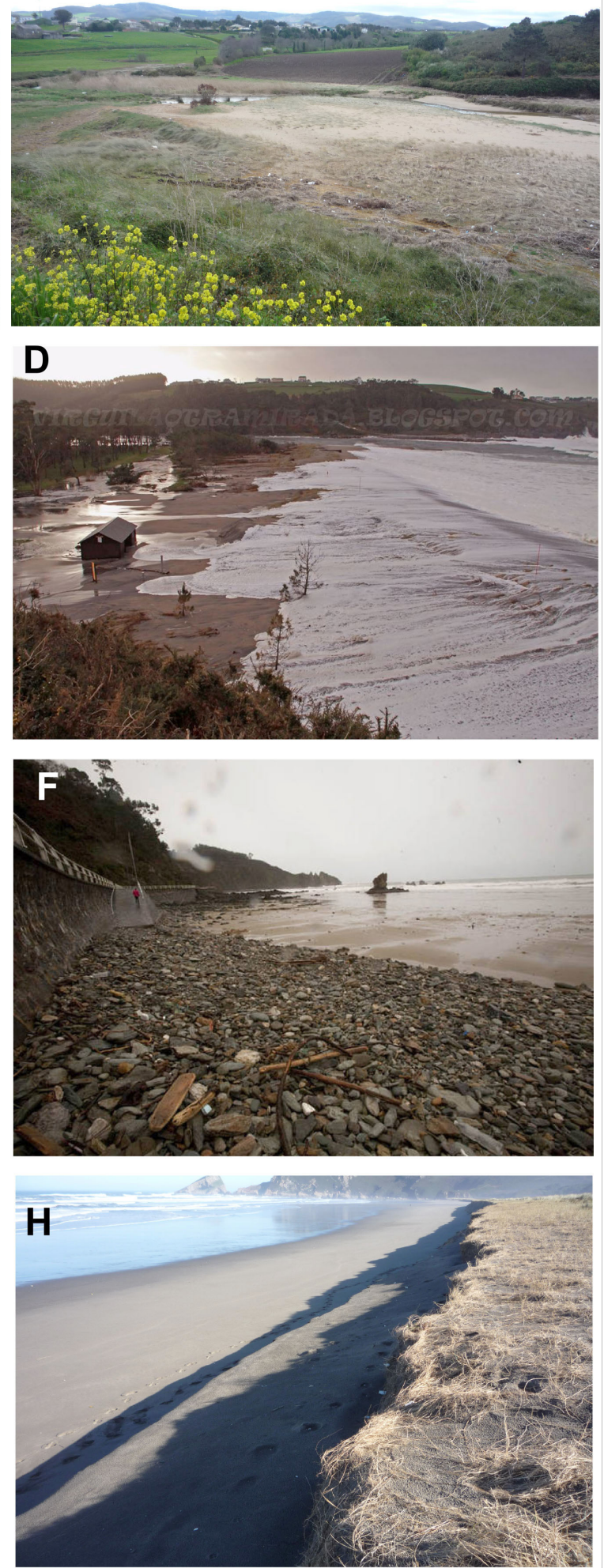

Figura 4. Algunas playas y dunas afectadas por los temporales de 2014. A) Playa y dunas remontantes de Mexota. B) Manto arenoso introducido en el estuario de Sarello. C) Erosión del recinto del campo de futbol de Tapia de Casariego e intrusión de un manto arenoso sobre el césped, que ocupa la bahía estuarina del Anguileiro. D) Playa y dunas de Navia en fase de inundación. E) Playa mixta de la Concha de Artedo. F) Playa de Aguilar. G) Los Quebrantos. H) Playón de Bayas. 
12. Frexulfe. Ha continuado la recesión variable de las dunas entre 1,0 $\mathrm{m}$ y 5,8 $\mathrm{m}$ en la horizontal y una intrusión menor de arenas aguas arriba del estuario. Diversos equipamientos de la playa, como las duchas, han sido arrasados.

13. Barayo. El retroceso de las dunas se ha cifrado en máximos de $18 \mathrm{~m}$ en la horizontal y con desniveles superiores a los $5,5 \mathrm{~m}$. Asimismo, se produjo una intrusión importante de arena, aguas arriba del estuario en todo el paso de desembocadura. En la margen oriental de la desembocadura, donde interactúan oleajes, mareas y viento, se sedimentó arena hasta el recodo agudo del canal principal, seguido de una erosión.

14. Otur. Ha sido una de las playas más afectadas, continuado la recesión de sus dunas, iniciada hace más de una década. La regresión calculada oscila entre 17 m y $48 \mathrm{~m}$ en la horizontal, con mayores retrocesos donde se ubican los accesos a la playa, donde se formaron a modo de bahías por adaptación de la erosión a estos pasillos.

15. Tercera de Luarca. Rebase de gravas al paseo donde la playa está encorsetada con un revestimiento de bloques inclinado hacia el mar. Daños en mobiliario y muretes de contención tras el camino que bordea la playa.

16. Cueva. Esta playa mixta de gravas y arenas conforma una barrera confinante en la parte alta del estuario del río Esva a cuyo pie se extiende un arenal extenso, incluso sobre el fondo sumergido. Esta barrera, construida solamente con gravas, dispone de un costado de sotavento a modo de una berma amplia que enlaza con una amplia superficie de posplaya. Las tormentas han generado mantos de gravas hacia el interior de la misma, adquiriendo una geometría tabular uniforme. En definitiva, el conjunto de la playa ha migrado, como lo viene haciendo irreversiblemente tierra adentro, que afectará en un futuro de la misma manera al conjunto estuarino del Esva.

17. Cadavedo. Playa mixta que ha rebosado gravas escasas en la zona central al situarse el pie del acantilado muy próximo en el resto de la playa. La berma de anchura métrica sobre la que se ubica una senda fue arrasada. Se ha llevado a cabo el despeje y reconstrucción de accesos y del borde de playa.
18. San Pedro de Luiña o de la Ribera. Esta playa, donde desemboca el río Esqueiro, ha concentrado amplias superficies de gravas especialmente en la franja intermareal superior. Se han desbordado abundantes gravas subangulosas sobre la superficie arenosa culminante, en lo que constituía un antiguo campo dunar removido. También se formó algún escarpe decimétrico sobre la parte alta de la playa en la mitad occidental.

19. La Concha de Artedo. Esta playa mixta culmina con una barrera que cierra la desembocadura del arroyo Uncín, desarrollando una costado de sotavento a modo de berma. El temporal ha formado mantos de tormenta de gravas, destruyendo la pasarela de madera en su mayor parte (Fig. 4E). Erosionó alguna vivienda en ambos extremos de la playa. Se ha advertido también una migración de la playa hacia tierra.

20. Aguilar. Se ha perdido gran volumen de arena, concentrándose cantos en la franja superior. Una franja de gravas imbricadas de unos 5-7 $\mathrm{m}$ de anchura, adosadas al paseo, principalmente, se reparten también por el resto de la playa (Fig. 4F). La plataforma rocosa afloró en diferentes sectores. Hubo daños en el mobiliario urbano.

21. Las Llanas. Desarrolló una franja de gravas en el intermareal superior donde emergieron afloramientos rocosos, habiendo perdido arenas y destrucción de los accesos.

22. Los Quebrantos. Esta playa arenosa contaminada parcialmente con arenas carbonosas y de escorias junto con las dunas culminantes, confina el estuario del Nalón. Se ha erosionado el límite dunar con el correspondiente retroceso, dejando escarpes métricos ( 8,3 y $16,5 \mathrm{~m})$. Se ha destruido la senda en la mitad occidental (Fig. 4G). Se han concentrado cantidad de troncos y plásticos en flotación sobre la franja superior de la playa, como es habitual en régimen de avenidas aportados por el Nalón.

23. Bayas. En esta extensa playa arenosa, mayoritariamente flanqueada por campos dunares en algo menos de 1,9 km de longitud en posición trasera, estas dunas han retrocedido hasta $25 \mathrm{~m}$ en la horizontal, quedando escarpes de más de $3 \mathrm{~m}$ en numerosos 
sectores y, localmente, algo superiores (Fig. 4H). Se han depositado gran cantidad de troncos y plásticos desde el Nalón.

24. Munielles. Playa mixta que ha perdido un gran volumen de arenas, concentrándose las fracciones de gravas de una manera más notoria. Los accesos a la playa han necesitado ser reparados en lo referente a la escalera y barandillas.

25. Bahinas. Se han transportado numerosos gravas hacia el camino de acceso, donde desagua el arroyo de Pisiesgo, formando una depresión que facilitó el desplazamiento del agua y sedimentos.

26. El Puerto o Santa Ma del Mar. Esta playa, que ocupa la desembocadura, donde se encaja el valle del arroyo de Ferrerías, está constituida por arenas finas con abundante fracción carbonosa aportada desde los lavaderos de las explotaciones de la Cuenca Carbonífera Central. Se intruyó arena sobre la zona supramareal y sobre la desembocadura, aguas arriba. La pasarela de madera, bancos y mesas situadas en la posplaya fueron arrasadas.

27. Arnao (Castrillón). La pérdida de arena fue especialmente importante, quedando la playa cubierta de gravas y algunos cantos desgastados, particularmente en la banda intermareal superior (Fig. 4I); afloró la plataforma rocosa, incluidos troncos estefanienses bien conservados, en amplias zonas.

28. Salinas. La pérdida de arena se incrementó, concentrándose gravas y escombros del antiguo paseo marítimo, que no se retiraron hasta esta ocasión en toda la playa intermareal central y occidental. Hubo un retroceso de más de $25 \mathrm{~m}$ del campo dunar en las proximidades del paseo marítimo, mientras que se mantuvo el campo oriental, que continua con un crecimiento muy lento. Buena parte de la acumulación arenosa sobre la playa oriental, retenida por el dique del estuario de Avilés, ha sido transportada hacia la bocana. Los dragados en ésta, justo después de los temporales, inducen a pensar se produjo un relleno de arenas sobre el canal de navegación procedentes de la recesión por las tormentas desde el frente dunar.

29. Playa estuarina de Zelúan, situada en la margen oriental del estuario de Avilés, fue barrida apor- tando un manto de arenas sobre la posplaya y campo dunar tabular. Las calles de la aldea de Zeluán se anegaron de barro y arena y hubo algunos destrozos en casetas.

30. Arañón. Esta playa de gravas y arenas, situada en la margen derecha del paso de desembocadura del estuario de Avilés, ha concentrado mayor proporción de gruesos. Donde hay tramos escollerizados, se han desplazado gran cantidad de gravas e, incluso, algún bloque sobre la zona supramareal, afectando a algunos bares y zonas recreativas.

31. Xagó. Esta playa recibe parte de los basculamientos de arenas y gravas de dragado en el estuario de Avilés, convirtiéndola en excedentaria (Flor-Blanco et al., 2013). La mitad occidental ha experimentado una ligera recesión del frente dunar y los correspondientes escarpes, pero se han introducido arenas con geometría de mantos de espesor centimétrico y decimétrico, que se distribuyen muy irregularmente sobre la otra mitad, afectando a la duna tabular exterior. En el extremo oriental del frente dunar, se formó un escarpe con desniveles del orden de 1,0 $\mathrm{m}$ a lo largo de unos $150 \mathrm{~m}$. La playa ha incrementado la proporción de fracciones groseras (superiores al tamaño arena). La recesión ha oscilado entre $3,1 \mathrm{~m}$ y $11,5 \mathrm{~m}$ en el sector centro occidental del frente dunar.

32. Carniciega o Aguilera. Como se viene registrando una recesión decamétrica del frente dunar en los últimos 45 años, los temporales de 2014 han erosionado más aún esta duna inactiva en torno a los 5-10 m horizontales, pero incrementando los desniveles hasta unos 8-9 $\mathrm{m}$, que dejan aflorar la arena sin fijación vegetal.

33. Tenrero. Se han erosionado los frentes de las dunas expuestas (mogotes lingüiformes y remontante occidental) entre 10 y $20 \mathrm{~m}$, construyéndose un lóbulo de tormentas entre ambos mogotes (Fig. 4J), de modo que ha avanzado aguas arriba del primer recodo septentrional del arroyo Biduero, rellenando el cauce por todo el trazado oriental.

34. Bañugues. Se ha erosionado más aún la terraza würmo-flandriense, que encorseta esta playa de arenas finas, y se produjo una intrusión menor de arena sobre la desembocadura del arroyo. La duna testimo- 

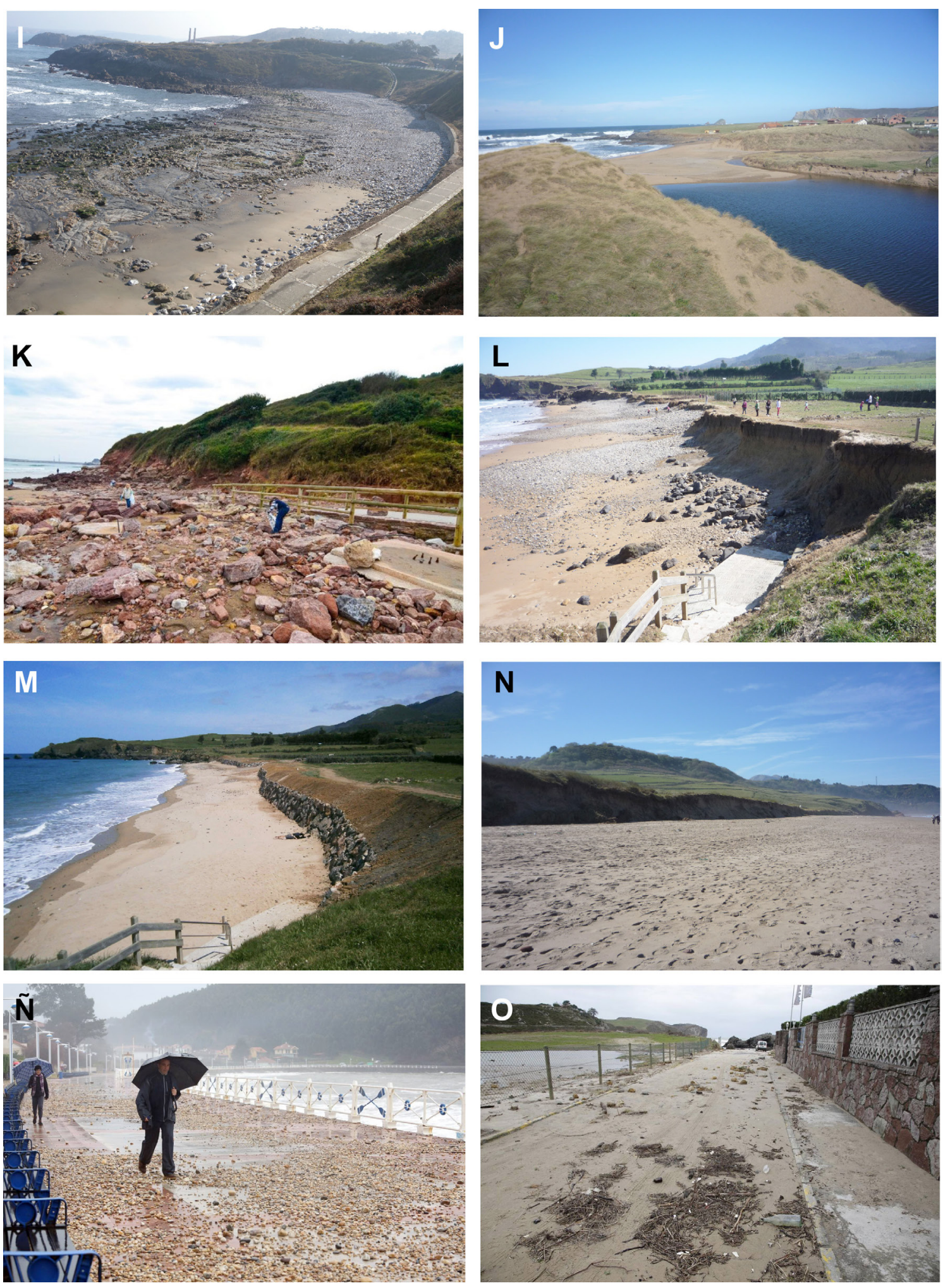

Figura 4 (continuación 1). I) Playa de Arnao (cedida por Hnos. Álvarez Lao). J) Lóbulo arenoso de tormenta que ha penetrado por el regato de la playa de Tenrero y márgenes erosionadas. K) Xivares. L) Terraza würmo-flandriense del segmento oriental de la playa de La Espasa, fuertemente erosionada. M) Escollera sobre esta misma terraza de La Espasa. N) playa de Vega y frente erosionado del campo dunar asociado. N) Paseo de Santa Marina invadido por gravas, construido sobre el frente dunar antiguo, por detrás del cual se urbanizó el campo dunar. O) Accesos a la playa de Borizo, situada al fondo. 
nial ha sido muy erosionada, evidenciando su crecimiento por sucesivas aportaciones de capas tabulares de material tipo zahorra y arena propiamente eólica, ambas de espesor decimétrico.

35. El Gayo (Luanco). Se han erosionado ambos extremos de la playa y arruinado el dique de contención, construido después de la regeneración de esta playa en los años 90 (Fig. 4T).

36. Aramar. Esta playa de gravas y gravillas en cuyo costado occidental desagua el arroyo de La Gallega ha retrocedido más de $10 \mathrm{~m}$ en horizontal, habiéndose erosionado el escarpe würmo-tardiflandriense y construido un amplio manto de tormentas muy uniforme hacia tierra. La franja sedimentaria de la playa se ha estrechado sustancialmente hasta 7-8 m, por término medio. Además, el temporal destruyó el puente de acceso desde el camino occidental.

37. San Pedro de Antromero. Hubo pérdida de arena de esta playa de por sí deficitaria, aflorando más superficie de plataforma rocosa de lo habitual. En la parte central de la playa, que es la más expuesta al oleaje incidente, se produjeron argayos en el acantilado trasero que taponaron temporalmente la comunicación entre los extremos de la playa.

38. Carranques. Gran desmantelamiento de arenas, incrementando los bordes rocosos confinantes, y la aparición de una mayor proporción de gravas y cantos.

39. Xivares. Sobre la zona supramareal, que es atravesada por el arroyo de Mouro, se desplazaron tierra adentro arenas, gravas y cantos con algún bloque para anegar el aparcamiento (Fig. 4K). El mobiliario como tuberías, platos de las duchas y pasos peatonales fueron destruidos.

40. San Lorenzo. Removilización del sedimento arenoso, conservando la berma de la playa supramareal todavía en fase constructiva, pero con una erosión parcial de las arenas de la esquina oriental (El Tostadero), donde afloró el sustrato rocoso. Tuvo lugar una intrusión importante de mantos y lóbulos arenosos aguas arriba del tramo canalizado del estuario del río Piles, que desemboca en la esquina oriental de la playa. Han sido numerosos los destrozos en el muro que ribetea la playa, incluidos elementos de piedras ornamentales de revestimiento (botaolas y pavimentos), edificio de servicios de playa, etc.

41. España. Cantos dispersos y mantos arenosos se han alojado en la parte alta de la playa donde desemboca el arroyo España, llegando aguas arriba. Parte de las arenas de la playa fueron desplazadas hacia la porción submareal. Afectó al paseo, pasarelas, escollera y área recreativa, así como a duchas, bancos y pasarelas.

42. Tazones. Esta playa encorsetada por un muro perdió gran cantidad de arena, en buena parte transportada hacia la explanada de la población, colgada respecto a la playa, a modo de mantos, así como cantos dispersos y algún bloque. Se concentraron cantos y gravas, preferentemente, en el área meridional.

43. Rodiles. La franja dunar externa se recuperó en la última década gracias al vallado disuasorio y ubicación de pasarelas de acceso a la playa en que la vegetación se colonizó de manera espontánea (Flor-Blanco et al. 2015), actuando de pantalla a las tormentas. Esta playa expuesta, perteneciente a la barrera confinante del estuario de Villaviciosa, ha experimentado alguna erosión del frente dunar, más acusada en la esquina oriental $(14,5 \mathrm{~m}) \mathrm{y}$, localmente, en algunos extremos de las pasarelas y el frente dunar con valores entre $1 \mathrm{y}$ $1,5 \mathrm{~m}$. Algunas láminas arenosas se extendieron irregularmente sobre la franja externa del campo dunar en las áreas central y occidental.

44. Misiego. En esta ensenada arenosa del estuario de Villaviciosa, se han producido escarpes erosivos (máximos de 0,50 m) en la duna estuarina de la barrera meridional y en algún sector de la duna más suroriental. Las dunas colonizadas por vegetación de Sarcocornia spp y Obione portulacoides, que bordean la llanura arenosa, han sido invadidas por arenas, suavizando el relieve del cordón existente, ahora más discontinuo, hasta desniveles centimétricos. El extremo meridional de esta bahía arenosa con el dique oriental limitante experimentó invasiones de arenas que migraron hacia el interior del estuario, un proceso que se ha magnificado con estos temporales, recubriendo parte de las marismas y el canal mareal de El Bornizal (marismas externas). 
45. La Griega. Fueron arrasadas las dunas tabulares de poca extensión ampliándose la berma, aunque quedó un retazo de dunas testimoniales. En la mitad oriental, se concentraron franjas de gravas y cantos en la banda más superior. En la esquina oriental, son mayores los afloramientos rocosos. El camping quedó recubierto de limos y arenas, al intruirse sedimento por el río Libardón, aguas arriba.

46. La Isla. El paseo de la playa de La Isla hacia la de Barrigón, quedó cubierto de arena por rebase desde las zonas inter y supramareal. Parte del frente dunar ha sido erosionado con escarpes cuyos desniveles fueron de medio metro y retrocesos importantes entre 8,5 y $10,5 \mathrm{~m}$. Se rompió parte del vallado del paseo y una de las placas de hormigón que cubren la desembocadura del saneamiento fue levantada.

47. La Espasa. Ha perdido abundante volumen arenoso, variable en la horizontal entre 1,5 y 10,15 $\mathrm{m}$, concentrándose gran cantidad de fracciones de gravas, que se continúan hacia la desembocadura del río Espasa. Se han depositado gravas sobre las dunas tabulares en su franja occidental, rebasando el paseo hacia el interior, e incluso en la franja situada al O de la desembocadura del río. La terraza würmo-flandriense del costado oriental (denominada como playa de El Viso) ha experimentado un gran retroceso en la porción trasera de la playa (Fig. 4L), llegando en algunos puntos a quedar justo sobre la senda litoral, antiguo camino de Santiago, hacia la playa de Beciella. Ha sido forrada con una escollera en la totalidad de su recorrido para reafirmar el sustrato, pero su afloramiento queda oculto definitivamente en lo que supone la pérdida de un hito patrimonial de carácter geológico costero muy importante (Fig. 4M).

48. Arenal de Morís. Esta playa encajada que, en condiciones de equilibrio, contiene franjas de gravas en sus dos ensenadas, separadas por un promontorio menor, y un extenso arenal hacia la bajamar, ha permitido que los temporales hicieran visible la plataforma de abrasión. Las olas de temporal se llevaron parte del vallado existente.

49. Vega. La desembocadura del arroyo Acebo en la parte oriental de la playa está ocupada por gravas, producto de avenidas. Los temporales han eliminado la fracción arenosa, ocupando estas gravas una mayor superficie. Por otra parte, el conjunto dunar ha sido erosionado intensamente con la aparición de escarpes en toda su extensión (2-3 m), más aún (3-4 $\mathrm{m})$ donde las acumulaciones de cordones dunares fueron más voluminosas y con retrocesos de hasta 7 m (Fig. 4N). Sobre el campo dunar oriental, constituido por dunas tabulares de poco relieve, se han alojado gravas dispersas. Los pasillos de acceso a la playa se han erosionado mucho más $(5 \mathrm{~m})$, generando a modo de ensenadas menores.

50. Santa Marina (Ribadesella). Como ya ocurriera durante temporales en los últimos años, se han concentrado las fracciones de gravas y gravillas en toda la playa emergida, llegando a rebasar mantos de estas fracciones (Fig. 4N) con algo de arena hacia el paseo marítimo. Se rompieron vallas, persianas y ventanas de algunas viviendas situada en primera línea de playa.

51. Cuevas de Mar. Esta playa se instala sobre el tramo inferior del valle del arroyo de Nueva o Ereba, aportador de grandes cantidades de gravas y gravillas, incluso durante estos episodios de tormenta, que determinaron la existencia de porcentajes elevados de estas fracciones sobre el lecho fluvial y franjas intermareal alto y supramareal. Los temporales las concentraron e, incluso, las transportaron hacia la posplaya, lo que ha afectado a la senda perimetral y áreas más alejadas. Se ha construido una berma neta de fracciones groseras, que se continúan por la mitad intermareal. Sobre la franja inferior, los cantos imbricados se han colonizados rápidamente por Enteromorpha spp, donde se desarrolla una terraza de bajamar arenosa en etapas de calma. Las arenas se han distribuido por la franja submareal somera, sin indicios de ser introducidas en la playa emergida después de 7 meses de oleaje de calma.

52. La Huelga es una playa estrecha que se abre en la desembocadura del arroyo San Cecilio, meandriforme en su tramo inferior, y deja márgenes arenosas hasta donde alcanzan las pleamares; el lecho activo está representado por gravas y la playa arenosa se extiende mejor por una franja oriental y otra expuesta a modo de una barrera confinante. Los temporales desplazaron gran cantidad de arenas hacia la por- 
ción sumergida, concentrando mayores superficies de fracciones groseras en la emergida. También, se depositaron capas de materia orgánica vegetal.

53. Gulpiyuri. La trasera de la playa, representada por una terraza sedimentaria, constituida por arcillas y limos de descalcificación, ha retrocedido unos centímetros con la formación de pequeños bloques de desprendimiento. Este proceso contribuyó a una ligera ampliación de la superficie intermareal. Los lavados del exterior de la playa han aportado algunas arenas silíceas, que se han canalizado hacia la superficie intermareal por una cárcava estrecha, excavando parte del reborde de la terraza.

54. San Antolín de Bedón o de Los Argaos. Esta amplia playa mixta, una parte de la cual constituye la barrera estuarina del río Bedón, ha construido un manto de tormenta proyectado hacia el canal principal. Parches de gravas rebasaron el eje del mismo, depositando mantos en la margen opuesta occidental. En el sector más occidental, donde la playa está más abrigada, se ubicaron también mantos de gravas sobre la playa supramareal, avanzando unas decenas de metros hacia tierra. Entre esta playa y la barrera estuarina, donde se produjo una gran acumulación de gravas y gravillas, los temporales erosionaron el prisma formando escarpes métricos, sin afectar al borde interno.

55. Barro. La superficie de aparcamiento de esta playa ha sido parcialmente erosionada en su borde que mira al mar. Esta estructura se apoyó sobre unas arenas pertenecientes a la playa arenosa original y ha concentrado gravas y cantos, así como materiales de construcción de tamaño bloque muy angulosos en todo su límite superior. Se ha destruido la escalera de hormigón que accede a la playa.

56. Borizo. Se ha removido toda la arena de la franja intermareal superior, aflorando arcillas de descalcificación generadas sobre el sustrato calcáreo, probablemente de origen periglacial en buena parte, pero continuándose la cubierta arenosa sobre el resto intermareal de la playa. Un amplio manto arenoso, relativamente homogéneo y limpio, de espesor centimétrico, se ha desplazado sobre el camino asfaltado de acceso de la playa, llegando a un centenar de metros hacia el interior (Fig. 4O). En la margen occidental se han producido argayos de material limoso-arcilloso y arenoso que delimitan la playa, formando parte de una posible terraza würmo-flandriense (?).

57. Portello. Han aflorado las arcillas de descalcificación y se ha producido una concentración de gravas $y$ cantos en la playa superior. También se han activado desprendimientos en casi todo el perímetro de la playa, constituido por limos y arcillas de alteración.

58. El Sablón (Llanes). Esta playa contiene un sedimento arenoso de espesor decimétrico a métrico (muy localizadamente), en condiciones de equilibrio, pero el temporal ha desplazado una capa arenosa sobre el paseo perimetral. Hacia el área submareal, ha quedado al descubierto el sustrato rocoso con arcillas de descalcificación y se han producido concentraciones de cantos y gravas en la parte superior (Fig. 4P). La franja inferior intermareal, que exhibe una mayor anchura y desarrolla en calmas una terraza de bajamar, ha aflorado el sustrato rocoso (área N), y recubrimientos delgados de gravas dispersas y gravillas en la franja meridional. El oleaje pone en suspensión fracciones arcillosas anaranjadas (Fig. 4Q). Se arrancaron parte de los bancos de este entorno y se intensificó la caída de bloques del acantilado, un proceso producido previamente, afectando nuevamente al talud NE anteriormente desprendido..

59. Toró. Ha quedado al descubierto el sustrato de limos y arcillas sobre las calizas carstificadas y se han concentrado cantos y gravas calcáreas en el acceso occidental (Fig. 4R), donde parte de este material se ha introducido hasta la carretera y el restaurante de la playa. Por otra parte, una extensa lámina de arena ha recubierto una superficie de unos $1.000 \mathrm{~m}^{2}$ en este mismo entorno urbanizado.

60. Andrín. Se han concentrado cantos y gravas, que presentan un buen grado de imbricación. La trasera de la playa, constituida por limos y arenas marrones, desde donde se accede, ha sido erosionada, así como parte de la pequeña plataforma de aparcamiento.

61. Bretones. Esta playa, también denominada de Novales, está dividida en dos ensenadas menores, la oriental más amplia y de planta arqueada. Está de- 

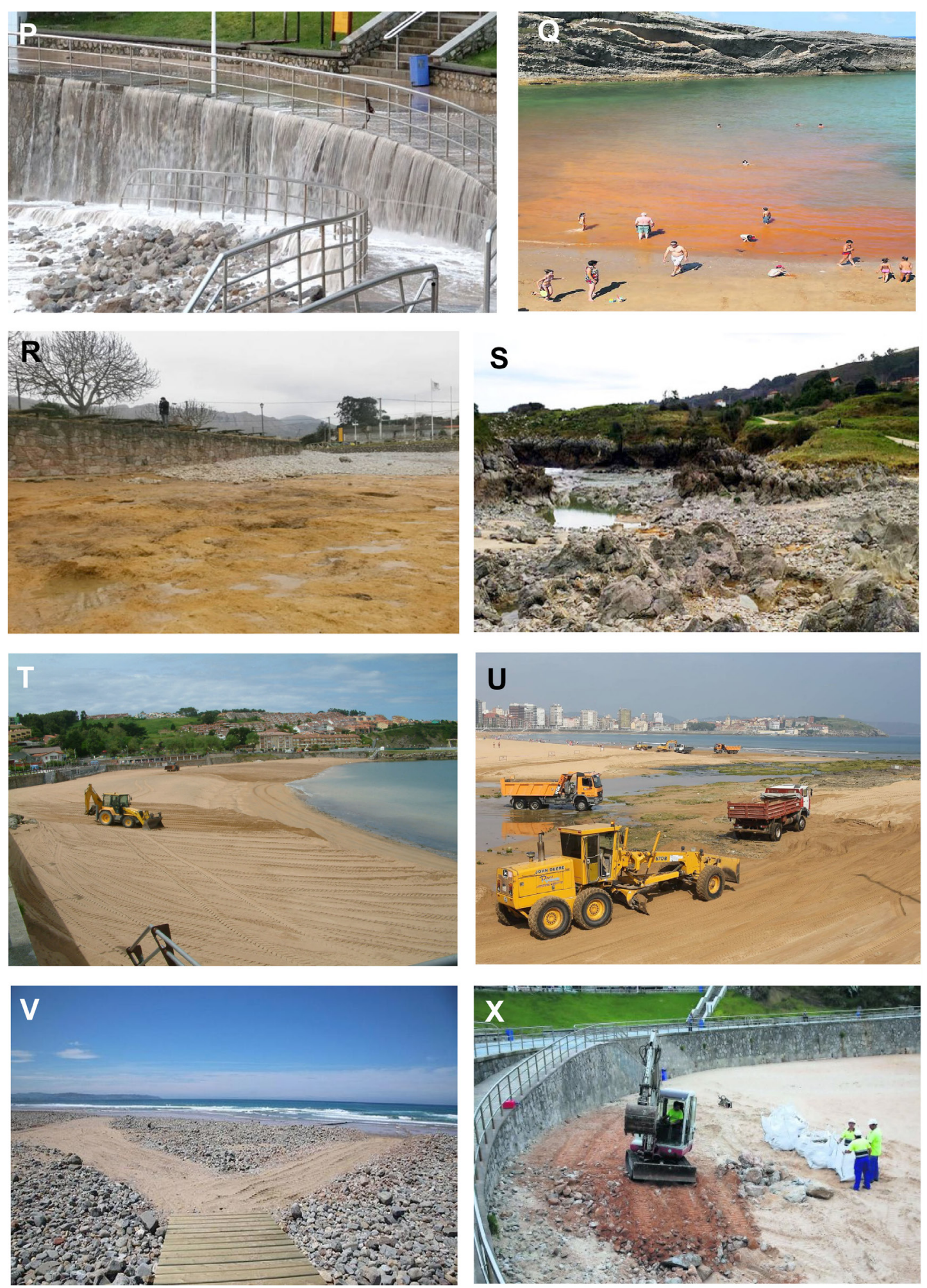

Figura 4 (continuación 2). P) Lavado de arenas y concentración de gravas en la parte alta de El Sablón y sobreelevación de la ola. Q) Puesta en suspensión de limos y arcillas de descalcificación de las calizas subyacentes en El Sablón de Llanes. R) Afloramiento de limos y arcillas de descalcificación en la playa de Toró. S) Parte alta de la playa de Buelna, desprovista de arena. T) Removilización in situ para configurar la berma y rebajar la pendiente en El Gayo. U) Trasvase de arena en San Lorenzo (toma al fondo y vertido en primer plano). V) Apertura de pasos arenosos en el intermareal entre la franja de gravas para acceder a la orilla del agua. X) Retirada de la banda de gravas y cantos supramareales en El Sablón. 
sarrollada sobre los materiales carboníferos, fundamentalmente terrígenos, que alberga un conjunto de arenas, que fueron parcialmente desmantelados de la playa emergida, incrementándose la proporción de fracciones groseras.

62. Castiellu o Pendueles. Está constituida por fracciones de cantos, gravas y arenas, las primeras casi en exclusiva, formando una barra casi perpendicular a la línea de costa, con mayor contenido en cantos. Éstas conectan con el islote de Piedras Llegüeras, formando un tómbolo. Sobre la playa, se suceden ambas fracciones permitiendo la formación de arcos o cúspides de playa en la mitad occidental, cuyas alas son preferentemente de gravas. Los temporales trasladaron una gran proporción de arenas a la playa sumergida.

63. Buelna o Arenillas. Ha quedado sin arena en la mayor parte de su porción emergida (Fig. 4S), pero concentrándose gravas y cantos en la parte oriental superior, donde aflora un sustrato rocoso irregular. Son calizas carstificadas muy irregularmente con un recubrimiento de arcillas y limos de descalcificación que, en todas las playas de las mismas características (Borizo, Portello, El Sablón y Toró), experimentaron puestas en suspensión de limos y arcillas (Fig. 4S). Representan, además, fondos muy resbaladizos para los usuarios. Éstas forman una franja estrecha en la playa superior recubierta por gravas y cantos para, hacia la bajamar, conservar un recubrimiento arenoso muy reducido.

64. Marimuerto. Este estuario se ha desarrollado sobre una dolina comunicada con el borde acantilado por una grieta subterránea y alberga un molino de marea censado en el Catastro de la Ensenada de 1752 (López Álvarez, 1998). Ha recibido aportes arenosos bajo la forma de un manto de espesor decimétrico, que ha recubierto parte de la marisma externa; asimismo, el delta mareal ha construido varios anillos hacia el interior.

65. Cobijero. El borde superior emergido, a modo de una berma colonizada por vegetación, se ha erosionado hasta quedar solamente un reborde irregular con una media de 1,0 m de anchura. Se ha incrementado ligeramente la proporción de gravas y cantos, en buena parte debido al desmantelamiento de la berma mencionada. Parte del acantilado occidental ha sido arrancado, cayendo bloques calcáreos sobre una de las entradas que alimentan esta playa interna. Además se ha abierto un nuevo "bufón" por delante de ésta.

\section{Discusión}

Es conocido que las playas son sistemas geomorfológicos que responden muy rápidamente a los cambios ambientales y experimentan episodios de erosión y crecimiento, sobre las que se hace particularmente importante la predicción de los cambios futuros en el largo plazo y a gran escala dentro del sistema costero (Whitehouse et al., 2009).

Los oleajes se constituyen en el factor energético fundamental en los cambios diarios, estacionales y a medio plazo de playas en lo que se refiere como clima de oleaje, aunque intervengan otros factores como mareas y vientos (Aubrey, 1983; Thorton et al., 2000; Dingler, 2005) a los que habría que incluir, a más largo plazo, los efectos derivados del ascenso del nivel del mar.

Se asumen, simplificadamente, los cambios cíclicos de playas arenosas en procesos de erosión (tormenta)-sedimentación (calmas prolongadas), bien documentados en todas las playas del mundo desde las primeras contribuciones de Shepard (1950) e Inman (1953) y, en particular, las asturianas (Flor, 1979; Flor y Flor-Blanco, 2009). En playas arenosas, las tormentas que actúan en tiempos muy cortos tienden a barrer las superficies supra e intermareal, hasta su aplanamiento, las más evolucionadas con bermas, e incluso la formación de abanicos de desbordamiento tierra adentro ("washover fans"), depositando el sedimento arenoso en la franja sumergida como barras y bancales (Bascom, 1953). La recuperación de las playas después de un evento erosivo suele ser relativamente rápida, pero está documentado que algunas han necesitado varios años después de tormentas intensas (Morton et al., 1994; Galgano et al., 1998), con tasas muy variables a lo largo de una costa homogénea y en periodos de varias décadas a más de un siglo (Galgano, 2008). Durante calmas de olas de periodo largo, se recompone el perfil de equilibrio y las barras arenosas sumergidas emigran 
hacia la orilla. La sucesión de ambos constituye el ciclo dinamo-sedimentario y morfológico de cualquier tipo de playa (Shepard, 1973).

En playas mixtas (Roberts et al., 2013), afectadas por huracanes y tormentas sucesivas en la costa atlántica de USA, se ha detectado un ciclo de playa diferente por el cual la playa atraviesa por un perfil transitorio inmediato a la tormenta con la formación de una barra emergida adosada a la posición anterior de la berma y, finalmente, un aplanamiento total del perfil de tormenta con la total ausencia de la barra o bancal arenoso.

También debe tenerse en cuenta, a más largo plazo, el proceso de la elevación del nivel del mar que, además de cambiar paulatinamente la configuración morfológica de la playa, puede incrementar el proceso erosivo o bien que los temporales se hagan cada vez más frecuentes e intensos (Yates et al., 2009b). En este caso, las playas evolucionan produciéndose una migración hacia tierra y una erosión de los frentes dunares asociados (Bruun, 1962; Dean, 1991; FitzGerald et al., 2008). En costas rocosas, como la cantábrica, se detectan numerosas playas en fase de acortamiento en su franja emergida (posplayas de Bañugues, Espasa, Bedón, etc).

En Galicia y la costa cantábrica, a primeros de febrero y marzo de 2014 se produjeron durante unas pocas horas unos eventos de tormentas extraordinarias, bajo condiciones de vientos y bajas presiones con olas de gran altura. Se produjo la erosión de los sedimentos playeros, preferentemente de la parte alta intermareal y retroceso del frente de dunas asociadas, y de parte o toda la superficie de la berma así como de algunas dunas estuarinas. Dichos eventos pueden ser catalogados como el resultado de una tormenta extratropical ("extratropical storm surge”) de Burroughs y Shaffer (1997), produciéndose una elevación anormal del nivel del mar como resultado de un oleaje de tormenta, por encima del nivel de las pleamares habituales, muy vinculados a huracanes en climas tropicales y subtropicales y donde las bajas presiones barométricas formaron parte del proceso de la sobreelevación del nivel del mar. El sumatorio del efecto derivado de la tormenta ("storm surge") y de la sobreelevación de la ola ("wave setup") puede alcanzar resultados extremos por los cuales el agua es capaz de rebasar los frentes dunares o erosionarlos (Gares, 1990) y con mayor eficacia si coinciden con pleamares vivas, como ocurrió en Asturias. Las circunstancias especiales de una persistencia de tales eventos en el tiempo ha promovido que se alcanzaran estas condiciones.

Para la mayor parte de las costas europeas, la influencia de las tormentas atlánticas se puede manifestar bajo la forma de ciclones extra-tropicales con una magnificación del denominado nivel del mar extremo, cuyos efectos han sido considerados como muy importantes en la protección costera (Weisse et al., 2014). El cambio climático global ha sido puesto en relación con el aumento de las frecuencias e intensidades de tormentas (Komar y Allan, 2008). Se han documentado en la costa oriental de USA a través de cálculos de las respuestas morfológicas en playas (Munger y Kraus, 2010) donde el retroceso en los complejos de islas barrera es dramático (Sallenger, 2000). En las costas gaditanas ha sido abordado por Benavente et al. (2006) mediante la consideración de dos tipos de tormentas características, modal y extrema con 1 año y 6-10 años de recurrencia, respectivamente, para lo cual se elaboraron mapas de riesgos para cada caso.

Obviamente, la totalidad de las playas asturianas han sido afectadas por estas tormentas en mayor o menor medida, sucediéndose los procesos derivados de la erosión de la playa en los dos sentidos opuestos, 1) hacia tierra por desbordamientos con la consiguiente sedimentación de mantos de arenas sobre las dunas o la playa alta y/o gravas, 2) avanzando la playa hacia tierra (Figs. 5A y B) y 3 ) por transporte mar adentro de las fracciones arenosas, concentrando bandas de gravas en la parte alta de la playa (Figs. 5C y D), que se extienden a la práctica totalidad intermareal. En playas abiertas sobre fondos rocosos calcáreos, quedaron al descubierto numerosos afloramientos de limos y arcillas de descalcificación, de forma particular en la parte alta intermareal (Figs. 5E y F); el hecho de que se concentren en el segmento oriental costero induce a pensar que los rellenos arenosos fueron paulatinamente menores hacia el $\mathrm{E}$ al decrecer el volumen arenoso disponible en el transporte litoral, durante la recuperación eustática holocena. 
Solamente algunos sistemas de playa/dunas interconectados lateralmente, que comparten el mismo prisma arenoso sumergido, experimentan la erosión de uno y la transferencia sedimentaria al contiguo (Mexota a Sarello y Carniciega a Tenrero, respectivamente), siempre hacia el E. Excepcionalmente, los dragados intensivos en los últimos 45 años del estuario de Avilés, han desencadenado un retroceso del frente dunar de Salinas (como parte de la barrera confinante estuarina), magnificado en este evento de temporales; contrariamente, los vertidos de parte de estos volúmenes de dragado sobre la playa sumergida de Xagó ha derivado en la formación de un nuevo campo dunar externo (Flor-Blanco et al., 2013).

Los campos dunares adosados a playas han mostrado dos comportamientos diferentes con el temporal, incluso coexistiendo en un mismo conjunto. Más generalizadamente, se han erosionado los frentes de la duna, dando lugar a escarpes de distinta magnitud, preferentemente con desniveles de escala métrica (Figs. 5G y H), mayores cuando se trata de dunas remontantes, como Mexota y Carniciega (Fig. 4H). Las dunas de Penarronda y Navia tuvieron este comportamiento en la mitad occidental y en Xagó, escasamente, en el extremo oriental, mientras que en el resto fueron recubiertas por amplios mantos arenosos de espesor decimétrico (Fig. 4D), a modo de abanicos de tormenta. La dunas externas de la playa de Xagó, constituidas por una manto tabular recibieron arenas como un manto centimétrico en el área oriental.

Las catalogadas en este trabajo se han limitado a las arenosas y mixtas, excluyendo las de gravas y gravillas muy numerosas en el occidente, que son estrechas (una o dos decenas de metros de anchura intermareal) al pie de acantilados abruptos y se apoyan sobre plataformas rocosas activas, con superficies apenas recubiertas por clastos. Numerosas playas arenosas, al desmantelarse un gran volumen arenoso, dejaron en superficie fracciones de gravas y cantos, que fueron concentradas por los oleajes incidentes en la parte alta de la playa y adquirieron las típicas imbricaciones de clastos; en algunas, ha aflorado el sustrato rocoso sobre segmentos o áreas de extensión muy variable que, en las calcáreas, descubren parches de limos y arcillas de descalcificación (Borizo, Sablón, Toró y Buelna).
Las playas mixtas han sido afectadas principalmente de modo que desmanteló parte de estas fracciones en la intermareal superior para construir mantos intrusivos sobre la posplaya, rebasando la cresta de la barra de gravas. En algunas, se ha detectado una migración neta de las barras tierra adentro deducida por la posición desplazada de las crestas de la berma (Fig. 5B: Porcía, Cueva y Bedón).

Habida cuenta de la gran importancia que representan las dunas, como reservas sedimentarias de arena para la futura recesión de la playa asociada (Sherman y Bauer, 1993; Rodríguez-Santalla et al., 2009; Houser y Ellis, 2013), ante las tormentas intensas y su consecuente retroceso, es obligado promover y preservar estas defensas naturales. La respuesta de estos ambientes se ha producido según los modelos evolutivos de Hesp (2002) con migración hacia tierra (Fig. 5G), en que se aportaron mantos arenosos eólicos (Xagó) o bien de tipo abanico o lóbulo de tormenta playero ("washover fan"), como en Navia y Penarronda. $\mathrm{O}$, simplemente, una erosión de buena parte o todo el frente (Fig. $5 \mathrm{H}$ ) con la consiguiente recesión, que fue lo más extendido: Penarronda, Sarello, Frejulfe, Barayo, Otur, Los Quebrantos, Bayas, Salinas, Xagó, Carniciega, Tenrero, Rodiles, Vega y Mexota (Fig. 5I). Algunas iniciaron este proceso desde hace una o dos décadas: Peñarronda, Mexota, Anguileiro, Navia, Frexulfe, Otur y Vega y la de Carniciega o Aguilera (Fig. 1) desde antes de 1960.

En playas donde desembocan arroyos costeros, se han reproducido dos modalidades de manera aislada o combinadamente. La intrusión de sedimento aguas arriba del canal principal en la franja estuarina con erosión parcial de los alrededores de la playa alta (Fig. 5J: Sarello, Anguileiro, Santa Ma del Mar, Tenrero, Bañugues, Xivares, España, San Lorenzo, La Griega, Cuevas de Mar) y la aportación intensa de fracciones groseras procedentes del arrastre fluvial, al coincidir con episodios de lluvias intensas, para conformar abanicos de gravas (Fig. 5K: Vega).

Justo después del primer temporal de febrero, comenzaron las obras de restauración de la obra civil, donde la autoridad de la Demarcación de Costas, depositaria de la gestión administrativa y técnica, ha puesto mayor énfasis, y para la segunda quincena del mes de junio de 2014 ya habían finalizado la limpie- 
za de las playas para dar servicio a los usuarios en la temporada de baños. La aportación del Servicio de Puertos del Principado, previa autorización, resolvió los casos de las playas del Sablón y Toró en el concejo de Llanes a finales de agosto, mediante vertidos controlados. También se ha procedido al fortalecimiento y reparación de daños en los diques de abrigo de numerosos puertos autonómicos, como Tapia de Casariego, Viavélez, Cudillero, etc.

Aunque sobre la mayoría de las playas no se ha intervenido, un cierto número ha recibido algunas soluciones muy diversas: 1) en playas donde se acumuló arena en la playa superior interna, se redistribuyó para conformar una nueva berma más amplia proyectada hacia el mar (Fig. 4T); 2) trasvase de arenas desde el intermareal inferior al superior (El Tostadero) en la playa de San Lorenzo de Gijón (Fig. 4U); 3) reutilización de arenas tomadas de la playa para uso como filtro de las aguas (solo $1.000 \mathrm{~m}^{3}$ ) en la piscifactoría de Cuevas de Mar; 4) en playas con una alta concentración de gravas en la franja superior, se han desplazado con medios mecánicos estas fracciones a entornos laterales de escaso uso, simplemente, como en Toró al pie de una escollera para su defensa, o bien sustituyéndolas por arenas tomadas en otro costado de la playa; 5) concentración de las gravas en una franja sobre la playa superior y extensión de una banda estrecha arenosa a modo de una senda de acceso en sentido transversal hasta la línea de bajamar media, como en Luiña, El Astillero de Lastres al NO de La Griega (no incluida en este trabajo), Cuevas de Mar (incompleta) y Vega (Fig. 4V). 6) Retirada de la totalidad de las fracciones de gravas, un hecho muy negativo para la estabilidad morfo-sedimentaria de la playa, en El Sablón (Fig. 4X); o retirada de una parte (Salinas). 7) En La Poza de Navia, se ha eliminado la banda arenosa adosada al dique de encauzamiento para facilitar un intercambio mareal más fluido con la consecuente mejor oxigenación de los fondos fangosos acumulados. 8) Autoalimentación consistente en el trasvase de arenas del frente sumergido de la playa a la playa emergida hasta conseguir una playa seca amplia. Esta técnica se ha aplicado, como sugirieron los autores en informes para el Servicio de Puertos del Principado, en el caso de las arenas a dragar en el puerto de Llanes y su trasvase a las playas de Toró y El Sablón por cuanto comparten el mismo prisma arenoso sumergido. Se vertieron $3.000 \mathrm{~m}^{3}$ mediante transporte en camiones a Toró y $5.000 \mathrm{~m}^{3}$ basculando, simplemente, la draga en el frente somero sumergido de la segunda. La Demarcación de Costas estudia la posibilidad futura de realimentar algunas playas del Concejo de Llanes con un volumen estimado de $23.000 \mathrm{~m}^{3}$ de un yacimiento arenoso de la plataforma continental, que llevaría a cabo para el año 2015.

Durante el verano de 2014, numerosas playas han repuesto buena parte del volumen de arena, pero manteniendo la franja de gravas en la playa alta, que necesitará ser recubierta en un futuro hasta consolidar un manto arenoso superficial continuo. En otras playas, la totalidad del sedimento arenoso no ha sido recuperado, ya que se desplazó hasta profundidades que dificultan su removilización por los oleajes de calma, pero que lo harán, probablemente, en el medio plazo (5 a 10 años) en caso de no persistir temporales de esta índole. Como apuntan Benavente et al. (2014), los cambios en las playas pueden superar los ciclos estacionales de modo que las oscilaciones están más relacionadas con la diferente intensidad de cada etapa invernal, en sentido amplio, y, consecuentemente, son necesarios varios periodos de recuperación. Es decir, algunos temporales de menor rango pueden ser capaces de removilizar los sedimentos a distintas profundidades para que los oleajes en las etapas de calma acaben culminando su transporte hacia la playa emergida y reconstruyan los perfiles de equilibrio, que implican un mayor relleno arenoso.

Este trabajo quiere llamar la atención sobre el litoral asturiano en lo referente a una gestión más adecuada de los ambientes intermedios (dragados en puertos y estuarios, cuyos vertidos deben hacerse sobre los sistemas de playa/dunas involucrados) y proteger algunos elementos patrimoniales geológicos (diferentes terrazas würmo-flandrienses, como las citadas) lo que requeriría un apoyo institucional para desarrollar trabajos de investigación futuros.

Asimismo, sugiere se lleve a cabo una mayor dedicación investigadora acerca de la evolución costera en los últimos 70 ańos, iniciada puntualmente en algunos reductos: estuarios del Nalón (Cabrera Ceñal y Flor, 1993) y Eo (Flor y Fernández Pérez, 1999; Flor y Flor-Blanco, 2011), sistema de playa/dunas de Xagó (Flor-Blanco et al., 2013), 
A)

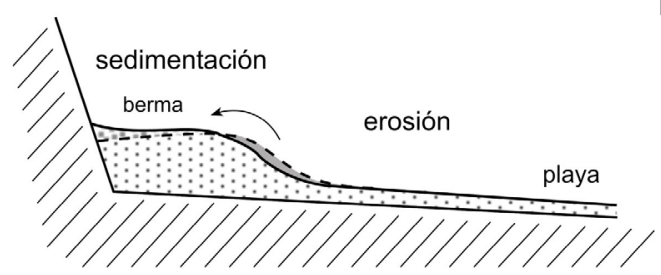

C)

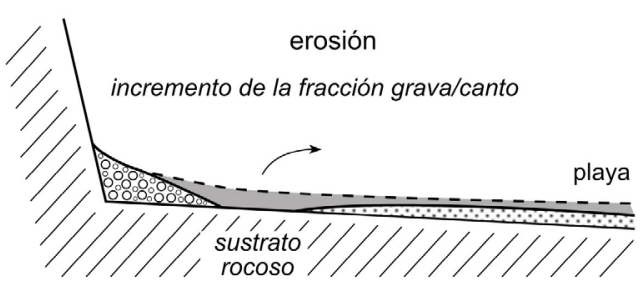

B)

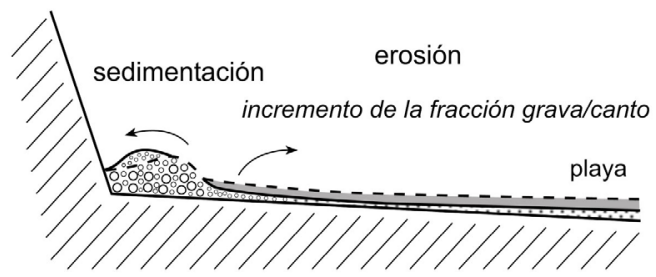

D)

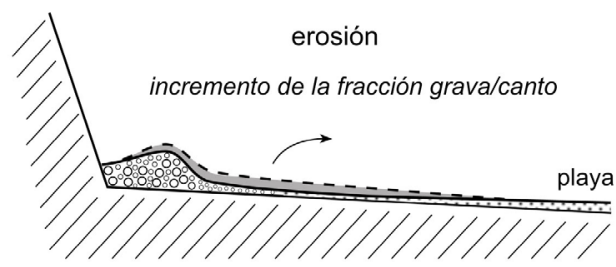

F)

desprendimiento

E)

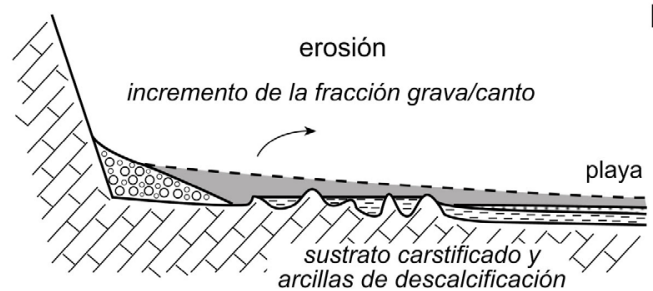

$\mathrm{G)}$

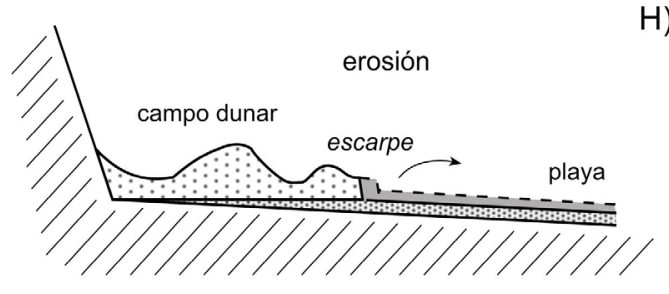

H)

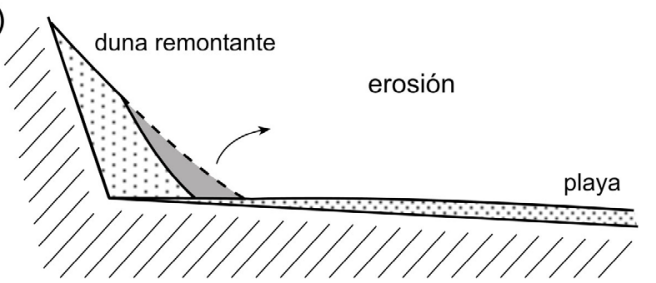

I)

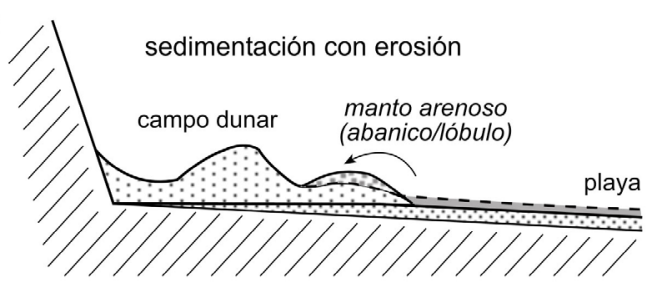

J)

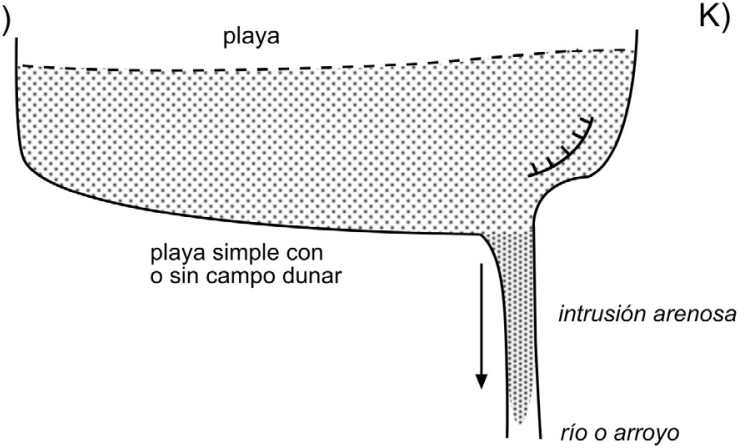

arenas dunares

manto/lóbulo de desbordamiento

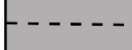

playa en equilibrio (pre-erosión)

ulescarpes y/o áreas erosionadas

desmantelamiento/intrusión de arenas

K)

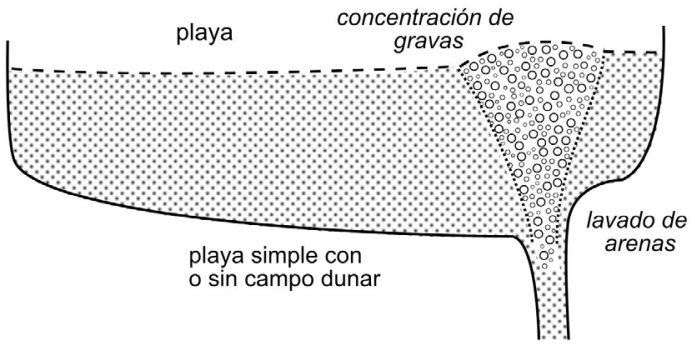

rio o arroyo

Figura 5. Modelos conceptuales reconocidos en playas y sistemas dunares asociados, así como de la influencia sobre algunos sistemas fluvio-estuarinos conectados a ciertas playas (sin escala). 
playas de Vega (Flor y Flor-Blanco, 2009), Rodiles (Flor-Blanco y Flor, 2009) y Bayas, que sirvan de base de datos para la toma de decisiones en un futuro con las garantías suficientes en el mantenimiento y recuperación de determinados espacios costeros. De este modo, se podrá disponer de una documentación de primera mano para predecir cambios futuros bajo condiciones de fuertes temporales y la consiguiente recuperación hasta que las playas alcancen el equilibrio dinamo-sedimentario y morfológico.

Justo después de la ocurrencia del último temporal de primeros de marzo, y durante la redacción de este trabajo, se vienen realizando controles morfológicos y sedimentarios con el objeto de determinar la evolución particular de cada playa hasta que alcancen las condiciones de equilibrio en lo pudiera constituir el ciclo típico o el más a largo plazo que, en las playas más afectadas sucederá en los próximos años.

\section{Conclusiones}

Los temporales extremos de febrero y marzo de 2014 provocaron provocó pérdidas o transferencias hacia tierra de volúmenes arenosos en playas y conjuntos de playa/dunas, algunas estuarinas, pero también de gravas y gravillas. Los mayores volúmenes arenosos experimentaron desplazamientos hacia la playa sumergida, incrementando sustancialmente las fracciones groseras (gravas) en el conjunto y concentrándolas en particular sobre la franja superior. Se produjo el consiguiente retroceso irreversible de los frentes dunares en todos los campos, con mayor incidencia en Salinas, asociado además a los dragados en el estuario de Avilés, y casi imperceptible en Xagó debido al excedente de aquéllos, mientras que la erosión del frente dunar de Carniciega, también muy acusada, mantiene más o menos equilibrada la sedimentación en la playa oriental de Tenrero.

En el caso de los sistemas de barreras confinantes (playa/dunas), algunas experimentaron una migración hacia tierra, superior a lo registrado en las últimas décadas. En los estuarios, en general, y en las desembocaduras de ríos y arroyos costeros, se produjo una intrusión sedimentaria de arenas aguas arriba, incluso hacia las márgenes del canal princi- pal, debido al ascenso del nivel del mar en curso, en general, y al proceso dinamo-sedimentario activo, en particular.

Los modelos propuestos ejemplifican los diferentes procesos ocurridos, de modo que sirvan para llevar a cabo una gestión de reposición o regeneración inmediata de carácter sedimentario en futuros eventos de tormenta, partiendo de una recuperación hasta alcanzar su equilibrio en un plazo estimado de un quinquenio.

Gracias a estos eventos catastróficos, se han podido identificar algunas playas, principalmente, dentro de la costa calcárea de Llanes cuyos rellenos arenosos son muy escasos, aunque muy extensos, donde afloran sustratos de limos y arcillas de descalcificación.

Desde la perspectiva medioambiental, la recuperación más sostenible en playas se deberá realizar mediante la aplicación de transferencias arenosas por medios mecánicos desde la propia playa emergida o desde el ámbito somero submareal (autoalimentación). En cuanto a la franja dunar limitante con la playa, se recomienda el vallado disuasorio e, incluso en condiciones muy negativas, proceder a una revegetación con especies propias de este medio eólico costero cantábrico.

En cambio, en determinados entornos, el retroceso supondrá la revisión, más o menos urgente, de la línea de Dominio Público Marítimo Terrestre y evaluar nuevas pautas de gestión del litoral.

\section{Agradecimientos}

Agradecer al Clúster de Energía y Medio Ambiente de la Universidad de Oviedo por la cesión de datos de las boyas instaladas en la plataforma continental asturiana y al Servicio de Cartografía del Principado de Asturias por el material topográfico y fotográfico entregado para el estudio. Asimismo, nuestro reconocimiento por las minuciosas revisiones a cargo de los Drs. Javier Gracia Prieto y Ramón Blanco Chao, con sus atinados comentarios $\mathrm{y}$ recomendaciones que han sido tenidos en cuenta en todo momento. 


\section{Bibliografía}

ANDROID (2013): $2^{\text {nd }}$ Annual Conference (Limassol, Cyprus). Proceed. $1^{\text {st }}$ ANDROID Residential Doctoral School. www. disaster-resilence.net

Anthony, E.J. (2013): Storm, shoreface morphodynamics, sand supply and the accretion and erosion of coastal dune barriers in the southern North Sea. Geomorphology, 198: 8-21.

Aubrey, D.G. (1983). Beach changes on coasts with different wave climates. En: Sandy beaches as ecosystems. En: A. McLachlan et al. (eds.). Developments in Hydrobiology, Springer, 19: 63-85.

Augustinus, P.G.E.F. (2003): Coastal systems. En: M. Sala (ed.) Theme 6.14, Geography. vol. 1. Encyclopaedia of Life-Support Systems (EOLSS) UNESCO, EOLSS, Oxford (UK), 12 pp.

http://www.eolss.net/Eolss-sampleAllChapter.aspx

BAsсом, W.H. (1953): Characteristics of natural beaches. Proceeding $4^{\text {th }}$ Coastal Engineering Conference. American Society of Civil Engineers: 163-180.

Benavente, J., Del Río, L., Gracia, F.J. y Martínez-del-Pozo, J.A. (2006): Coastal flooding hazard related to storms and coastal evolution in Valdelagrana spit (Cadiz Bay Natural Park, SW Spain). Continental Shelf Research, 26: 1061-1076.

Benavente, J., Puig, M., Del Río, L. y Plomatiris, T.A. (2014): ¿Pueden los inviernos suaves recuperar el perfil de una playa? En: S. Schnabel y Á. Gómez Gutiérrez (eds.). Avances de la Geomorfología en España 2012-2014. Actas de la XIII Reunión Nacional de Geomorfologia, Cáceres: 548-551.

Birkemeier, W.A. (1985): Time scale of nearshore profile change. Proceeding Coastal Engineering '85, ASCE, New York: 1507-1521.

Bruun, P. (1954): Coastal erosion and development of beach profiles. Technical Memoir, 44. U.S. Army Corps of Engineers, Washington D.C, 79 pp.

Bruun, P. (1962): Sea-level rise as a cause of shore erosion. Journal of Waterway, Port, Coastal and Ocean Engineering, American Society of Civil Engineers, 88: 117-130.

Burroughs, L.D. y Shaffer, W.A. (1997): East coast extratropical storm surge and beach erosion guidance. NWS Technical Procedures Bulletin, 436. National Oceanic and Atmospheric Administration, US Department of Commerce. Silver Spring, MD 20910, 11 pp.

Cabrera Ceñal, R. y Flor, G. (1993): Evolución reciente del estuario del Nalón (Asturias). Cuaternario y Geomorfología, 7: 23-34.

Ciavola, P., Ferreira, O., Haerens, P., van Koningsveld, M., Armaroli, C. y Lequeux, Q. (2011): Storm impacts along European coastlines. Part 1: the join effort of the MICORE and ConHaz Projects. Environmental Science \& Policy, 14: 912-923.
Conde Criado, J. (2014): Episodios de oleaje intenso en las costas del Cantábrico durante el periodo octubre-1957 a marzo-2014. Aemet, 37 pp.

http://www.aemet.es/documentos/es/noticias/2014/Analisis_ Episodios_Oleaje_Intenso_V4.pdf

Dail, H.J., Merrifield, M.A. y Bevis, M. (2000): Steep beach morphology changes due to energetic wave forcing. Marine Geology, 162: 443-458.

DAvIS, R.A. y Fox, W.T. (1972): Coastal processes and nearshore sand bars. Journal of Sedimentary Petrology, 42: 402-412.

DeAn, R.G. (1991): Equilibrium beach profiles: characteristics and applications. Journal of Coastal Research, 7: 53-84.

Dingler, J.R. (2005): Beach Processes. En: M. L. Schwartz (ed.). Encyclopedia of Coastal Science. Springer: 161-168.

FitzGerald, D.M., Fenster, M.S., Argow, B.A. y Buynevich, I.V. (2008): Coastal impacts due to sea-level rise. Annual Review of Earth and Planetary Sciences, 36: 601-647.

FLOR, G. (1978) Relación entre la circulación costera y la distribución de sedimentos en la región de Cabo Peñas. Trabajos de Geología, 10: 183-194.

FLOR, G. (1979): Depósitos arenosos de las playas de la región de cabo Peñas (Asturias): sedimentología y dinámica. Tesis Doctoral (inédita), Departamento de Geología, Universidad de Oviedo.

Flor, G y Fernández Pérez, L.A. (1999): Manejos y evolución en el estuario del Eo (Galicia-Asturias, NO de España). En: L. Pallí Buxó y C. Roqué Pau (eds.). Avances en el estudio del Cuaternario español. Actas de la X Reunión Nacional del Cuaternario, Girona: 37-42.

Flor, G. y Flor-Blanco, G. (2009): Sedimentología de los depósitos arenosos superficiales de playa de Vega (Concejo de Ribadesella, Asturias). Revista de la Sociedad Geológica de España, 22: 105-121.

Flor, G y Flor-Blanco, G. (2011): Guía de Campo. La influencia humana sobre las playas y estuarios de Galicia oriental y Asturias occidental. GEOLODÍA-11. Sociedad Geológica de España. 45 pp.

Flor, G. y Flor-Blanco, G. (2014a): Raised beaches in the Cantabrian coast. En: F. Gutiérrez y M. Gutiérrez (eds.). Landscapes and Landforms of Spain, Springer: 239-248.

Flor, G. y Flor-Blanco, G. (2014b): Guía de Excursiones. Dinámica y sedimentación aplicadas a la gestión costera. Máster en Recursos Geológicos e Ingeniería Geológica. Servicio de Publicaciones, Universidad de Oviedo, 152 pp.

Flor, G. y Flor-Blanco, G. (2014c): Guía de Excursiones. Geología Marina. Grado en Geología. Servicio de Publicaciones, Universidad de Oviedo, 132 pp.

Flor, G., Llera E.Ma y Ortea, J.A. (1982): Los carbonatos biogénicos de los sedimentos de las playas arenosas de Asturias y Cantabria: su origen y significado dinámico. Cuadernos del CRINAS, 2: 1-77. 
Flor-Blanco, G. y Flor, G. (2009): Aspectos geomorfológicos del tramo inferior del estuario de Villaviciosa (Asturias) en relación con su evolución histórica. Revista de la Sociedad Geológica de España, 22: 123-136.

Flor-Blanco, G., Flor, G. y Pando, L. (2013): Evolution of the Salinas-El Espartal and Xagó beach/dune systems in north-western Spain over recent decades: evidence for responses to natural processes and anthropogenic interventions. Geo-Marine Letters, 33: 143-157.

Flor-Blanco, G., Pando, L., Morales, J. A. y Flor, G. (2015). Evolution of beach-dune fields systems following the construction of jetties in estuarine mouths (Cantabrian coast, NW Spain). Environmental Earth Sciences, 73(3): 1317-1330.

Galgano, F.A. (2008): Shoreline behaviour along the Atlantic coast of Delaware. Middle States Geography, 41: 74-81.

Galgano, F.A., Douglas, B.C. y Leatherman, S.P. (1998): Trends and variability of shoreline position. Journal of Coastal Research, 26: 282-291.

García-Artola, A., Cearreta, A. y Leorri, E. 2014. Relative sea-level changes in the Basque coast (northern Spain, Bay of Biscay) durong the Holocene and Anthropocene: The Urdaibai estuary case. Quaternary International (2014), http://dx.doi.org/10.1016/j.quaint.2014.06.040.

Gares, P.A. (1990): Predicting flooding probability for beach/ dune systems. Environmental Management, 14: 115-123.

HARPER, J.R. (1980): Seasonal changes in beach morphology along the B.C. Coast. Canadian Coastal Conference 1980: 136-150.

Haxel, J.H. y Holman, R.A. (2004): The sediment response of a dissipative beach to variations in wave climate. Marine Geology, 206: 73-99.

Hesp, P. (2002): Foredunes and blowouts: initiation, geomorphology and dynamics. Geomorphology, 48: 245-268.

Hill, H.W., Kelley, J.T., BelKnap, D.F. y Dickson, S.M. (2004): The effects of storms and storm-generated currents on sand beaches in Southern Maine, USA. Marine Geology, 210: 149-168.

Houser C. y Ellis J. (2013): Beach and dune interaction. En: J. F. Shroder (ed.). Treatise on Geomorphology, 10, Academic Press, San Diego: 267-288.

InMAN, D.L. (1953): Areal and seasonal variations in beach and nearshore sediments at La Joya, California. Technical Memoir 39. Beach Erosion Board, U.S. Army Corps of Engineers, Washington D.C. 82 pp.

Komar, P.D. y Allan, J.A. (2008): Increasing hurricanegenerated wave heights along the U.S. east coast and their climate controls. Journal of Coastal Research, 24: 479-488.

LEAS (2012): Climatología Aeronáutica. Aeropuerto de Asturias. Guia resumida del clima (1998-2011). AEMET, 112 pp.

Lee, G., Nicholls, R. y Birkemeier, W.A. (1998): Stormdriven variability of the beach-nearshore profile at Duck North Carolina, USA, 1981-1991. Marine Geology, 148: 163-177.
Leorri, E., Horton, B.P. y Cearreta, A. (2008): Development of a foraminifera-based transfer function in the Basque marshes, N. Spain: implications for sea-level studies in the Bay of Biscay. Marine Geology, 251: 60-74.

López Álvarez, J. (1998): Molinos de mar en Asturias. Fundación Municipal de Cultura, Educación y Universidad Popular. Ayuntamiento de Gijón. 18 pp.

Lotze, F. (1945): Zur gliederung der Varisziden der Iberischen Meseta. Geotekt. Frosch., 6, 78-82. Berlín. (Traducido por Ríos, J.M. (1950): Observaciones respecto a la división de los varíscides de la Meseta Ibérica. Publicaciones Extranjeras sobre la Geología de España: 149-166).

Loureiro, C., Ferreira, O. y Cooper, J.A.G. (2014): Nonuniformity of storm impacts on three high-energy embayed beaches. En: A.N. Green y J.A.G. Cooper (eds.). Proceeeding $13^{\text {th }}$ International Coastal Symposium (Durban, South Africa). Journal of Coastal Research, Special Issue, 70: 326-331.

Masselink, G. y Pattiaratchi, C.B. (2001): Seasonal changes in beach morphology along the sheltered coastline of Perth, Western Australia. Marine Geology, 172: 243-263.

Mederos Martín, L. (2009): Las mareas. Actualizado el 31 de marzo de 2009. 61 p. http://www.rodamedia.com/navastro/ mareas/mareas_LMederos.pdf.

Morton, R.A., Payne, J.G. y Gibeaut, J.C. (1994): Stages and durations of post-storm beach recovery, south-eastern Texas coast, USA. Journal of Coastal Research, 10: 884-908.

Munger, S. y Kraus, N.C. (2010): Frequency of extreme storms based on beach erosion at Northern Assateague Island, Maryland. Shore \& Beach, 78: 3-11.

Nordstrom, K.F. (1980): Cyclic and seasonal beach response: a comparison of ocean and bayside beaches. Physical Geography, 1: 177-196.

Pinazo Ojer, J. Ma 2010. Condiciones climáticas exteriores de proyecto. Guia técnica. Ahorro y eficiencia energética en climatización 12. IDAE.

http://asesoramentotecnico.coag.es/wpcontent/ uploads/2010/02/guia_12_condiciones_climaticas_v05.pdf.

Rangel-Buitrago, N. y Anfuso, G. (2013): Winter wave climate, storms and regional cycles: the SW Spanish Atlantic coast. International Journal of Climatology, 33: 2142-2156.

Rodríguez Ramírez, A., Cáceres, L.M., Rodríguez Vidal, J. y Cantano, M. (2000): Relación entre el clima y génesis de crestas/surcos de playa en los últimos cuarenta ańos (Huelva, Golfo de Cádiz). Cuaternario y Geomorfología, 14: 109-113.

Roberts, T.M., Wang, P. y Puleo, J.A. (2013): Storm-driven cyclic beach morphodynamics of a mixed sand and gravel beach along the Mid-Atlantic Coast, USA. Marine Geology, 346: 403-421.

Rodríguez Santalla, I., Sánchez García, M.J., Montoya Montes, I., Gómez Ortiz, D., Martín Crespo, T. y Serra Raventós, J. (2009): Internal structure of the aeolian sand dunes of El Fangar spit, Ebro Delta (Tarragona, Spain). Geomorphology, 104: 238-252. 
Ruggiero, P., Kaminsky, G.M., Gelfenbaum, G. y Voigt, B. (2005): Seasonal to interannual morphodynamics along a high-energy disssipative littoral cell. Journal of Coastal Research, 21: 553-578.

Sallenger, A.H., Jr. (2000): Storm impact scale for barrier islands. Journal of Coastal Research, 16: 890-895.

Sánchez-Arcilla, A., Gracia, V., García, M. y Solé, J.M. (2012): Predicción morfodinámica operacional. Una nueva estrategia de gestión litoral. En J.M. Barragán Muñoz (coord.). Comunicaciones I Congreso Iberoamericano de Gestión Integrada de Áreas Litorales (GIAL): 1167-1182.

http://hum117.uca.es/grupogial/paginas/cursosymaster/icongresogialiberoamerica/comunicaciones-i-congreso-iberoamericano-de.pdf

Sénéchal, N., Gouriou, T., Castelle, B., Parisot, J.-P., Capo, S., Bujan, S. y Howa, H. (2009): Morphodynamic response of a meso- to macro-tidal intermediate beach based on a long-term data set. Geomorphology, 107: 263-274.

Shepard, F.P. (1950): Beach cycles in southern California. Technical Memoir 20, Beach Erosion Board. U.S. Army Corps of Engineers, Washington D.C. 26 pp.

Shepard, F.P. (1973): Submarine Geology (3a ed). Harper\&Row, Publications N.Y., 517 pp.

Sherman, D. J. y Bauer, B. O. (1993): Dynamics of beach-dune systems. Progress in Physical Geography, 17: 413-447.

ShorT, A.D. Ed. (1999): Handbook of Beach and Shoreface Morphodynamics. Wiley and Sons. Chichester (UK), 379 pp.

Taylor, R.B., Frobel, D., Forbes, D.L. y Mercer, D. (2008): Impacts of post-tropical storm Noel (November, 2007) on the Atlantic coastline of Nova Scotia. Geological Survey of Canada, Open File 5802, 90 pp.

Thorton, E., Dalrymple, R.A., Drake, T.G., Elgar, S., Gallagher, E.L., Guza, R.T., Hay, A.E., Holman, R.A., Kaihatu, J.M., Lippmann, T.C. y Ozkan-Haller, H.T. (2000): State of nearshore processes research. II. Naval Postgraduate School Technical Report NPS-OC-00-001. California 93943.

http://www.coastal.udel.edu/coastal/nearshorereport/nrwreport.html

Weisse, R., Bellafiore, D., Menendez, M., Mendez, F., Nicholls, R.J., Umgiesser, G. y Willems, P. (2014): Changing extreme sea levels along European coasts. Coastal Engineering, 87: 4-14.

Whitehouse, R., Balson, P., Beech, N., A., Brampton, A., Simon Blott, Burningham, H., Cooper, N., French, J., Guthrie, G., Hanson, S., Nicholls, R., Pearson, S., Pye, K., Rossington, K., Sutherland, J. y Walkden, M. (2009): Characterisation and prediction of large-scales, longterm change of coastal geomorphological behaviours: Final science report. Science Report: SC060074/SR1. Environmental Agency \& Defra, 264 pp.

https:/www.gov.uk/government/uploads/system/uploads/attachment_data/file/291152/scho0809bqvl-e-e.pdf
Wijnberg, K.M. y Kroon, A. (2002): Barred beaches. Geomorphology, 48: 103-120.

Wright, L.D., Short, A.D. y Green, M.O. (1985): Short term changes in the morphodynamic states of beaches and surf zones: an empirical predictive model. Marine Geology, 62: 339-364.

Yates, M.L., Guza, R.T., O’Reilly, W.C. y Seymour, R.J. (2009a): Overview of seasonal sand level changes on southern California beaches. Shore \& Beach, 77: 39-46.

Yates, M.L., Guza, R.T. y O’Really, W.C. (2009b): Equilibrium shoreline response: Observations and modeling. Journal of Geophysical Research, 114: C09014.

\section{Otros enlaces}

Cluster de Energía, Medioambiente y Cambio climático. Universidad de Oviedo. http://cei.uniovi.es/energia/novedades/-/asset_publisher/71TU/content/la-boya-oceanografica-de-la-universidad-registra-una-ola-de-20-metros-a-cuatro-kilometros-de cudille; jsessionid=9F49DC75276093845940F1F80EABF26D?p_r_p_564233524_ tag=fecha_y2014,fecha_m02

CONGEO. 2013. Dinámica litoral, medio biótico y análisis de sedimentos en el estuario del río Anguileiro. Anexo 5. Al estudio de Impacto Ambiental. ftp://ftp.asturias.es/asturias/ industria/mineria/EIA_SALAVE/anexo_5_dinamica_litoral_medio_biotico_analisis_sedimentos_estudiario_anguileiro.pdf

Datos meteorológicos del puerto de El Musel, los días 2 de febrero y 3 de marzo de 2014:

https://www.puertogijon.es/index.asp?MP=5\&MS=55\&M$\mathrm{N}=3 \& \mathrm{TR}=\mathrm{C} \& \mathrm{IDR}=556 \& \mathrm{fechaDia}=02 / 02 / 2014$

https://www.puertogijon.es/index.asp? MP=5\&MS=55\&M$\mathrm{N}=3 \& \mathrm{TR}=\mathrm{C} \& \mathrm{IDR}=556 \& \mathrm{fechaDia}=03 / 03 / 2014$

http://www.aemet.es/documentos/es/serviciosclimaticos/vigilancia_clima/resumenes_climat/mensuales/2014/res_ mens_clim_2014_02.pdf

http://www.aemet.es/es/serviciosclimaticos/datosclimatologicos/superacion_umbrales? $\mathrm{p}=33 \& \mathrm{w}=0$

http://www.aemet.es/documentos/es/serviciosclimaticos/vigilancia_clima/resumenes_climat/mensuales/2014/res_ mens_clim_2014_03.pdf

http://www.rtve.es/alacarta/audios/eureka/eureka-invierno-temporales-24-02-14/2413790/

Instituto de Hidráulica Ambiental de Cantabria, WebUC (López Lara, J. y Vidal, C.)

http://www.unican.es/WebUC/Internet/Noticias_y_novedades/Noticias/20140217+b.htm

Oleaje extraordinario en el Cantábrico y Galicia. http://www. puertos.es/content/oleaje-extraordinario-en-el-cantabrico-y-en-galicia 
